\title{
مدى انطباق نظرية القوة القاهرة على جائحة فيروس كورونا في إطار العقود المدنية (SARS-CoV-2)
}

\author{
تأليف الدكثور

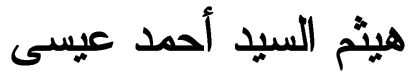 \\ دكتور اه في القانون المدني
}




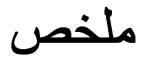

قد أثرت جائحة فيروس كورونا (SARS-cov-2) على تتفيذ الالتزامات العقدية، بأن جعلتها مستحيلة التتفيذ في بعض الحالات، بسبب التدابير الحكومية التي تتخذها الدولة لمواجهة الفيروس أو الآثار الناتجة عن الإصابة به أو مخاطر العدوى أو العو اقب الاقتصادية الناشئة عن انتشاره؛ الأمر الذي جعلنا نفكر في بحث موضوع مدى انطباق القوة القاهرة على الآثار الناتجة عن تلك الجائحة، وذلك لكي نوضح الأساس القانوني الذي يمكن للمدين أن يستند عليه في نفي مسئوليته العقدية التي قد تتشأ عن عدم تتفيذ العقد؛ وهو ما اقتضى منا تقسيم هذا البحث إلى مطلبين؛ وضحنا في الأول تحديد المقصود بالقوة القاهرة وبينا في الثاني تطبيق شروط تحقق القوة القاهرة على جائحة فيروس كورونا (SARS-cov-2).

الكلمات المفتاحية: جائحة فيروس كورونا، القوة القاهرة، الالتز امات العقدية، المسئولية العقدية.

\section{Abstract}

The coronavirus pandemic (SARS-cov-2) has impacted the performance of contractual obligations by making them impossible to fulfill in some cases, due to government measures taken by the state to counteract the virus, the infection with it, risks of infection, or the economic consequences of its outbreak; this made us think about studying the topic of the extent to which the force majeure theory applies to the effects of that pandemic, in order to clarify the legal basis on which the debtor can rely on in proving lack of its contractual liability that may arise from non-performance of the contract; which required us to divide this research into two sections, in the first, we clarified the meaning of force majeure and in the second, we clarified the application of the conditions for the emergence of force majeure to the coronavirus pandemic (SARS-cov-2).

Keywords: coronavirus pandemic, force majeure, contractual obligations, contractual liability. 


\section{مقدمة}

فيروسات كورونا Coronavirus هي مجموعة من الفيروسات التي تسبب أمر اضناً تصيب الجهاز التتفسي، تثراوح شدتها من نز لات البرد العادية إلى الأمر اض شديدة الخطورة مثل متلازمة الشرق الأوسط التنفسية "ميرس" (MERS-CoV) الذي أكتشف عام 2012، ومتلازمة الالتهاب الرئوي الحاد الوخيم "سارس" (SARS-CoV) الذي أكتشف عام 2003؛ وفي ديسمبر عام 2019 بدأ تفشي فيروس جديد من عائلة الفيروسات التاجية (كورونا) في مدينة ووهان الصينية، وقد أطلقت عليه اللجنة الدولية لتصنيف الفيروسات (ICTV) إسم فيروس كورونا 2 المسبب لمتلازمة الالتهاب الرئوي الحاد الوخيم (SARS-CoV-2) ونم إختيار هذا الإسم لله نظر ا لارتباطه الجيني بفيروس كورونا المسبب لمتلازمة الالتهاب الرئوي الحاد الوخيم "سارس"، وعرُف أيضا المرض الذي يسببه هذا الفيروس المستجد بإسم كوفيد-19 (Covid-19) وهو مرض معد ينتقل عن طريق القُيرات الصغيرة "الرزاز" المتتاثرة من أنفم أو فم الشخص المصاب عند العطس أو السعال أو الكلام، و التي يلتقطها شخص آخر بالتفس، إذا كان على مسافة قريبة، أو بلمس الأسطح أو الأشياء التي ثقع عليها ثلك القطير ات ثم لمس الفم أو الأنف أو العينين بعد ذلك. وقد أعلنت منظمة الصحة العالمية في تاريخ 30 يناير 2020 بأن تفشي فيروس كورونا المستجد يشكل طارئة صحية عمومية تسبب قلقاً دولياً une urgence de santé publique de portée internationale (USPPI) يعني ذلك أن الفيروس أصبح حدثا إستثائيا يشكل خطرا محتملا يحدق بالصحة العمومية في الدول الأخرى، وذلك بسبب انتشار المرض دوليا مما قد يقتضي استجابة دولية منسقة. وفي تاريخ 11 مارس 2020 أعلنت المنظمة بأن تفشي فيروس كورونا المستجد أصبح جائحة Pandémie، وتعني الأخيرة، وفقا للمنظمة، تفشي مرض جديد ينتشر بسهولة من شخص لآخر في جميع أنحاء العالم. وهذا غير الوباء Épidémie الذي ينتشر بسرعة بين عدد كبير من البشر في منطقة معينة أو مجمو عة سكانية معينة، مثال ذلك وباء "سارس" ووباء "الإيبو لا". ويختلف ذلك 
أيضا عن المرض المستوطن Endémie الذي ينو اجد بصورة دائمة في منظقة جغرافية معينة أو بين مجموعة محددة من السكان، مثال ذلك مرض "جدري الماء".

\section{1-موضوع البحث}

بعد أن تفشى فيروس كورونا مُسببا أزمة صحية عالمية؛ بدأت الدول في إعلان حالة الطوارىء أو اتخاذ إجر اءات استثنائية للحد من انتثار الفيروس ومكافحته، واختلفت الإجر اءات التي اتخذت لاحتو اء تفشي الفيروس ومواجهته، من دولة إلى أخرى، بحسب مدى انتشار الفيروس وخطورنه في الدولة وتقدير الموقف من قبل الحكومة إز اء ذلك؛ فهناك دول فرضت حظر ا عاما؛ بحيث ألزمت المواطنين بعدم الخروج من المنازل ومنع التجوال إلا للضرورة أو فيما يتعلق بممارسة الأنشطة الحيوية في الدولة، فضلا عن تعطيل العديد من المر افق العامة و إغلاق عدد من المنشآت المختلفة، وهناك دول فرضت حظر ا جزئي؛ بحيث يتقيد المواطنون و أصحاب الأعمال بأوقات محددة، يسمح لهم بالخروج والحركة أو العمل خارج المنزل خلالها فقط، مع تعطيل بعض المرافق و إغلاق بعض المنشآت أو تخفيض عدد العاملين بها، و المقصود من عرض ذلك بيان أن الأمر لم يكن على وتيرة واحدة في كل الدول العالم، وإن كان هناك تدابير مشتركة بين الدول كتعليق حركة الطيران و إغلاق المطار ات و المو انىء البحرية والمنافذ البرية، إلا للضرورة كإجلاء بعض العالقين ومساعدة الدول الأخرى وكذلك القيام بعمليات استيراد وتصدير السلع و البضائع المختلفة وما يرتبط بها في حدود ما قدرته الدولة لمواجهة الأزمة، لأن هناك بعض الدول أوققت تصدير بعض السلع، كما في مصر؛ فقد منعت تصدير بعض البقوليات، ومن الإجراءات المشتركة أيضا بين الدول حظر التجمعات، كحضور جماهير كرة القدم أو إقامة المؤتمر ات و الحفلات ودخول الملاهي ودور السينما وخلافه، بالإضافة إلى إتباع إجراءات الحجر الصحي quarantaine بشأن المشتبه في إصابتهم أو الأشياء المشتبه في تلوثها، و إتباع إجر اءات العزل Isolement بشأن الأشخاص المصابة أو الأشياء الملوثة.

وقد كان لتالك التدابير و الإجر اءات و القرار ات المختلفة أثز ا كبير ا على حياة الأفر اد بمختلف صورها وكذلك أنشطة الثركات والأشخاص الاعتبارية بوجه عام، وانعكس ذلك بجلاء في 
قدرتهم على تتفيذ الالتز امات التعاقدية التي تقع على كاهلهم؛ و أصبح هناك تساؤل يتعلق بالحالات التي يستحيل على المدين فيها تتفيذ النزامه، حول السند القانوني الذي يسنطيع الاحتجاج به لنفي la force obligatoire مسئوليته العقدية التي قد تتشأ عن ذلك في ظل مبدأ القوة الملزمة للعقد du contrat قاعدة أنه لا التزام بمستحيل A l'impossible nul n'est tenu، ويتمثل ذلك في نظرية القوة القاهرة Force majeure لأنها جاءت لنواجه الأحداث التي تطر أ بعد إبرام العقد وتجعل تتفيذ الالتزام أمر ا مستحيلا على المدين، بغية تحقيق العدالة النعاقدية بين الطرفين في النهاية؛ ولذا يتحدد موضوع در استتا في بحث مدى انطباق تلك النظرية على جائحة فيروس كورونا المستجد.

\section{2-إشكالية البحث}

قد اتضح من السطور السابقة أن فيروس كورونا (SARS-CoV-2) هو فيروس جديد، و هذا يعني، وفقا لمنظمة الصحة العالمية، أن الكثير عنه ماز ال مجهو لا، بالإضافة إلى أنه ماز ال ينتشر ولم ينته بعد، وهناك آثار مختلفة تتجم عنه يمكن أن تسبب استحالة تنفيذ الالتزام، وينطلب الحكم بوصف أي منها بالقوة القاهرة أن ينت تطبيق شروط تحققها عليه أو لا لبيان مدى استجابته لها، و هذا يقتني الإلمام بخصوصية كل أثر لتقييم المسألة، وفي نفس الوقت ينبغي أن يتم ذلك من خلال معيار واحد ينطبق على كافة الحالات ويعكس التوقعات المعقولة للمتعاقدين؛ فلا يصح في ظل عدم وضوح هذا الفيروس وبحجة عدم اليقين الذي برتبط به أن يتم تطبيق نظرية القوة القاهرة عليه كما لو كان حدثا عاديا نستجلي حقيقته بالقياس على أحداث أخرى لا تتثابه معه أو نضحي بتطبيق النظرية كلية أو نخرجها من دائرة نوقعات المتعاقدين بحيث يندر تطبيقها على و واقع تلك الجائحة.

\section{3-أهمية البحث}

يساهم هذا البحث في بيان كيفية إعمال نظرية القوة القاهرة فيما يتعلق بالآثار الناجمة عن جائحة فيروس كورونا المستجد، و التي تجعل من تتفيذ العقد أمر ا مستحيلا؛ وهذا يعني أننا نحاول 
من خلاله تقديم حلولا قانونية للإشكاليات المتعلقة بخصوصيات تفشي الأوبئة أو الجوائج عند انطباق شروط تحقق القوة القاهرة عليها، وعلى وجه الخصوص جائحة فيروس كورونا المستجد، بما يمثله ذلك من رفع المعاناة عن المدين حيال ظروف تخرج عن إرادته ويمكن أن ينرتب عليها

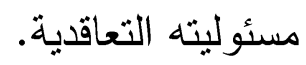

\section{4-صعوبات البحث}

تتمثل صعوبات هذا البحث في حداثة الموضوع؛ فالدر اسات المتعققة التي تتاولته قليلة بالنظر إلى حجم الأزمة الصحية التي يمر بها العالم الآن وما ترتب عليها من عدم القدرة على تتفيذ الالتزامات التعاقدية في بعض الحالات، بالإضافة إلى أن الدراسات التي أُجريت بخصوص أونئ أوبئة أو جو ائح سابقة والتي يمكن الاهتداء بها عند إجر اء دراسة عن جائحة فيروس كورونا المستجد، قليلة أيضا، كما أن عدم إختفاء الفيروس حتى كتابة هذه السطور يفضي إلى عدم اليقين حول الآثار التي قد تتتج عنه في المستقبل و انعكاساتها على تتفيذ العقود المدنية ويساهم في ذلك عدم وجود لقاح أو علاج لمواجتها، وبالتالي فإن الموضوع في كثير من جو انبه ماز ال يكتنفه الغوض و هو ما يمثل صعوبة في تتاوله و الحكم على المسائل المختلفة التي يثيرها. 5-المنهج العلمي

سنقوم في هذا البحث باتباع المنهج النحليلي التأصيلي لكي نستطيع سبر أغوار الآثار الناجمة عن الفيروس وبيان طبيعتها وتطبيق شروط تحقق القوة القاهرة عليها لبيان مدى استجابتها لها، كما أننا سنعتمد أيضا على المنهج المقارن وذلك عن طريق تطبيق تللك الثروط وفقا للقانون المصري والفرنسي وسنركز على النطبيقات القضائية التي نظرت أمام القضاء الفرنسي فيما

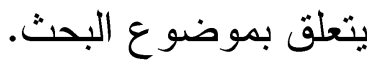




\section{6-خطة البحث}

سنقوم بمحاولة تقديم الحل القانوني لإشكالية البحث السابق بيانها والتغلب على صعوباته من

خلال تحديد المقصود بالقوة القاهرة بداية ثم تطبيق شروط تحققها على جائحة فيروس كورونا المستجد (SARS-cov-2)؛ ولذا سنقسم هذا البحث إلى مطلبين كالتالي:

المطلب الأول: تحديد المقصود بالقوة القاهرة

المطلب الثاني: تطبيق شروط تحقق القوة القاهرة على جائحة فيروس كورونا (SARS-cov-2) 


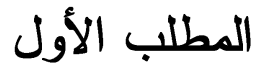

\section{تحديد المقصود بالقوة القاهرة}

لم يضع المشرع المصري تعريفا للقوة القاهرة، ومع ذلك قضت محكمة النقض المصرية بأن القوة القاهرة بالمعنى الوارد في المادة 165 من القانون المدني تكون حربا أو زلزالا أو حريقا، كما قد تكون أمرا إداريا واجب التتفيذ، بشرط أن يتوافر فيها استحالة التوقع واستحالة الدفع. وينقضي بها التزام المدين من المسئولية العقدية، وتنتفي بها علاقة السببية بين الخطأ والضرر في المسئولية التقصيرية، فلا يكون هناك محل للتعويض في الحالتين 1.

ويعرفها البعض بأنها أمر غير متوقع الحصول وغير ممكن الدفع يجعل تتفيذ الالتز ام مستحيلا دون أن يكون هناك خطأ من جانب المدين². ويذهب البعض إلى أنها حادث خارجي لا يمكن توقعه و لا دفعه، يؤدي مباشرة إلى حدوث الضرر 3. كما يرى البعض أنها كل فعل لا شأن لإز ادة

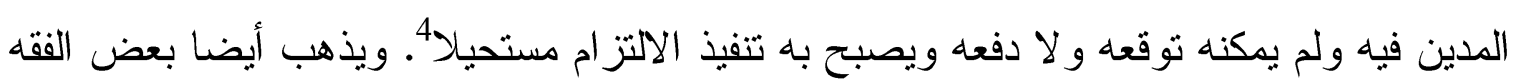
إلى أنها الو اقعة التي تتشأ باستقال عن إرادة المدين و لا يكون باستطاعته توقعها أو منع حدوثها ويتزتب عليها أن يستحيل عليه مطلقا الوفاء بالتز امهـ.5

وقد وضع المشرع الفرنسي تعريفا للقوة القاهرة في المادة 1218 من القانون المدني، والتي أُضيفت بمقتضى القانون رقم 131-2016 بشأن إصلاح قانون العقود والنظرية العامة

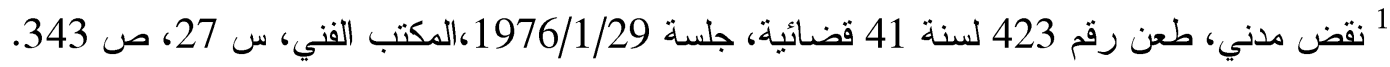

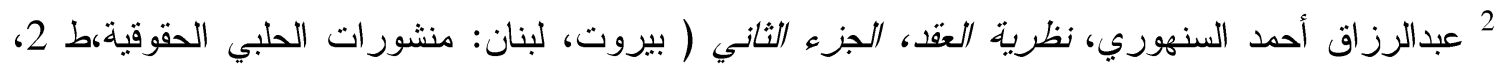
. 1998)، 963 3 محمد لبيب شنب، الدسئولية عن الأشياء دراسة في القانون المدني المصري مقارنا بالقانون الفرنسي(القاهرة:

مكتبة النهضة المصرية، 1957)، 97. 4 محمد محيي الدين سليم، نظرية الظروف الطارئة بين القانون الددني والفقه الإسلامي( الاسكندرية: دار الدطبو عات الجامعية، 2007)، 528.

${ }^{5}$ Roger Dufourmantelle, La force majeure dans les contrats civils ou commerciaux et dans les marches administratifs (Paris: Giard et Briere, 1920), 12. 
للالتزامات و الإثبات، و الذي صدر في 10 فبر اير 2016 ودخل حيز النفاذ في 1 اكتوبر من نفس العام؛؛ حيث نصت على أنه " تتحقق القوة القاهرة في المسائل التعاقدية عند وقوع حادثة خارجة عن سيطرة المدين، لم يكن من الممكن توقعها بشكل معقول وقت إبرام العقد، و لا يمكن تجنب آثار ها باتخاذ إجر اءات مناسبة، وتحول دون قيام المدين بتنفيذ التز امهُ 7.

وقضت أيضا محكمة النقض الفرنسية فيما يتعلق بهذا الثأن بأن " القوة القاهرة التي تسمح بإعفاء صاحب العمل من كل أو بعض التزاماته الناشئة عن الإخلال بعقد العمل تعني وقوع حدث خارجي لا يمكن مقاومته يجعل من المستحيل الاستمر ار في العقد الدذكور.

6 للمزيد من التفاصيل بشأن هذا القانون، أنظر : بن خدة حمزة، "قراءة في أهم مستجدات الإصلاح الجذري

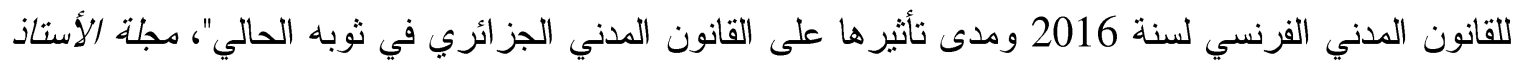
الباحث للار/سات القانونية والسياسية، عدد 11(سبتمبر 2018): 418-447.

${ }^{7}$ Article 1218: I| y a force majeure en matière contractuelle lorsqu'un événement échappant au contrôle du débiteur, qui ne pouvait être raisonnablement prévu lors de la conclusion du contrat et dont les effets ne peuvent être évités par des mesures appropriées, empêche l'exécution de son obligation par le débiteur.

${ }^{8}$ Cass.soc, 12 Février 2003, $n^{\circ} 00-46660$, Bulletin 2003 V N ${ }^{\circ} 50$ p. 45 ;

وراجع أيضا للمزيد من التعريفات للقوة القاهرة: Isabelle de Taddéo, "LA NOTION DE FORCE MAJEURE", (Janvier 2005): 1-3. http://jl.droit.free.fr/docs/La\%20notion\%20de\%20force\%20majeure.pdf .(1/4/2020). 


\section{المطلب الثاني}

\section{تطبيق شروط تحقق القوة القاهرة على جائحة فيروس كورونا (SARS-CoV-2)}

يتضح لنا من النعريفات التي بيناها في المطلب الأول أن هناك أربعة شروط يجب تو افرها في الحادث لكي يوصف بأنه قوة قاهرة، وهي وجوب أن يكون حادثا خارجيا، ليس في الإمكان توقعه، كما لا يمكن مقاومته ويجعل تتفيذ الالتزام مستحيلا؛ وسوف نقوم بتطبيق هذه الشروط على جائحة فيروس كورونا (SARS-CoV-2) في هذا المطلب لكي نبين مدى تحقق القوة القاهرة فيما يتعلق بهذا الثأن، وذلك على النحو التالي:

\section{Extérieur أو لا: حادث خارجي}

ينبغي أن يكون الحادث المُشكل للقوة القاهرة مستقلا عن إرادة المدين؛ أي ألا يكون للمدين دخل في وقو عه 9. وقد أكدت محكمة النقض المصرية على ذلك؛ حيث قضت بأنه " لما كان إثهار إفلاس شركة الطاعنين والمطعون ضده الأول والتحفظ على أموال الثركاء فيها كان مرجعه 9

Roger Masamba Makela, "L'IMPOSSIBLE ET LE CONTRAT", (2015): 9.

http://www.daldewolf.com/documents/document/2015122111503247_52_roger_masam ba_I_x27_impossible_et_le_contrat_fv1_09_02_14.pdf.(15/3/2020); Jean VAN ZUYLEN, "La force majeure en matière contractuelle: unconcept unifié? Réflexions à partir des droits belge, français et hollandaise", Revue Générale de Droit Civil Belge Kluwer, TBBR/RGDC (2013): 416.

https://dial.uclouvain.be/pr/boreal/object/boreal\%3A124936/datastream/PDF_01/view. (15/3/2020); Sandra DUMOND, LA DATE ET LE CONTRAT, (Thèse de doctorat, Université Lyon III, FACULTE DE DROIT, 2003), 112.

http://www.theses.fr/2003LYO33035. (15/3/2020). 
تعثز ها و امتناعها عن سداد ديونها التجارية وهو أمر راجع إليها ومتوقع الحدوث في مثل هذه

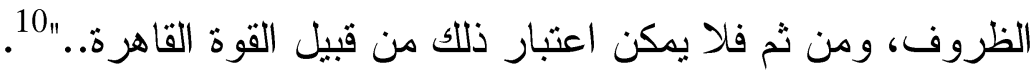

وقد ظهر هذا الثرط جليا أيضا في أول حكم قضائي في فرنسا يتتاول تطبيق القوة القاهرة على جائحة فيروس كورونا المستجد و يعترف بأن مخاطر العدوى بفيروس كورونا المستجد تعد قوة قاهرة، وهو الحكم الذي أصدرته محكمة استئناف كولمار في تاريخ 12 مارس 2020، في قضية تتعلق بحقوق الأجانب، لم بتمكن فيها المستأنف من حضور جلسة المحكمة، نظر اللاشتباه في إصابته بفيروس كورونا المستجد، في مركز الاحتجاز الاداري (CRA)، والذي يحتجز فيه. وقد قضت المحكمة بأن هذه الظروف الاستثنائية circonstances exceptionnelles التي أدت إلى غياب السيد AX في جلسة اليوم، تأخذ طابع القوة القاهرة force majeure، كونها خارجية، لايمكن التتبؤ بها و لايمكن مقاومتها، بالنظر إلى المهلة الزمنية المحددة للحكم، وحقيقة أنه من غير المكن في هذه المدة التأكد من عدم وجود خطر العدوى، والحصول على حراسة موكول بها أخذ السيد Ax إلى جلسة الاستماع، بالإضافة إلى أن مركز الاحتجاز الإداري CRA أثشار إلى أنه لم يكن لايه المعدات اللازمة لسماع السيد AX عبر الفيديو كونفر انس Visio conference، مما يعني أن منل هذا الحل غير ممكن أيضان. . وقد أكدت محكمة استئناف كولمار موقفها السابق في 10 نضض تجاري، طعن رقم 20133 لسنة 77 قضائية، جلسة 2010/4/27. https://www.cc.gov.eg/judgment_single?id=111263005\&\&ja=83999. (16/3/2020). ${ }^{11}$ CA Colmar, ch. 6 (etrangers), 12 mars 2020, n²0/01098. https://www.doctrine.fr/d/CA/Colmar/2020/C8A8F3A305EEEBB31F249 .(28/3/2020);

Sophie Latieule, "COVID-19 ET LOCATIONS MEUBLÉES TOURISTIQUES : LES CONDITIONS D'ANNULATION À L'ÉPREUVE DE LA FORCE MAJEURE", Fidal (7/4/ 2020) . https://www.fidal.com/fr/actualites/covid-19-et-locations-meubleestouristiques-les-conditions-dannulation-lepreuve-de-la .(15/4/2020); Séverine Tavennec, "Contrats et covid-19 : quid de la force majeure ?", Le petit jurist 
أحكام صدرت في قضايا أخرى، في تاريخ 16، 23 مارس 2020، و التي اعنبرت فيها أيضا الظروف الاستثائية الناشئة عن فيروس كورونا قوة قاهرة تبرر الغياب عن الجلسات، و تتمثل بصفة أساسية في مخاطر نقل العدوى إلى الغير، و على وجه الخصوص الموظفين المطلوبين لضمان عقد الجلسة، والتي تبرهن عليها تدابير الاحتواء التي اتخذتها الدولة لهنع تفشي الفيروس

وقضت أيضا محكمة استئناف بواتييه في تاريخ 24 فبراير 2012 بأن حجز البضائع، الأقنعة، المستوردة في الجمارك بسبب عدم مطابقتها للمواصفات المطلوبة، وقت انتشار فيروس انفلونزا الطيور، لا بشكل قوة قاهرة أو سببا لإعفاء المدين من التعويض عن عدم التسليم أو النسليم المتأخر، ذلك أنه كان يجب عليه إختيار مورد موثوق به والتحقق من أن الأقنعة سيتم تصنيعها وفقا للمعايير المعلن عنها313. وهذا يعني أن المحكمة رأت أن حجز الأقنعة المسنوردة كان بسبب خطأ المدين ذاته.

وقد بينت المو اد 165، 215، 373 ددني مصري ذلك؛ حيث إن المسئولية المدنية تنتفي وفقا للمادتين 165، 215 إذا نشأ الضرر عن سبب أجنبي لا يد للمدين فيه، وتعد القوة القاهرة، أول مظاهر السبب الأجنبي، كما هو معروف في القواعد العامة ووفقا لنص المادة 165، $==(3 / 4 / 2020)$. https://www.lepetitjuriste.fr/contrats-et-covid-19-quid-de-la-forcemajeure/ $\cdot(15 / 4 / 2020)$.

${ }^{12}$ CA Colmar, ch. 6, 16 mars 2020, $\mathrm{n}^{\circ}$ 20/01142 et 20/01143; CA Colmar, ch. 6, 23 mars 2020, n² 20/01206 et 20/01207 ; Olivier Nicolas, "Coronavirus : Peut-on invoquer la Force Majeure ?", echos (6 avril 2020). https://echosjudiciaires.com/actualite/tribune-coronavirus-force-majeure/.(27/3/2020).

${ }^{13}$ CA Poitiers, 1re ch., 24 févr. 2012, n 11/02200. https://www.doctrine.fr/d/CA/Poitiers/2012/BE28434296C65B106A64F .(1/4/2020). 14 محمد شتا أبو سعد، "مفهوم القوة القاهره، مجلة مصر المعاصرة، الجمعية الدصرية للاقتصاد السياسي والإحصاء والثتريع 78، عدد 394،393(1983): 178، 179؛ و نتص المادة 165 على أنه: إذا أثبت الثخص أن الضرر قد نثأ عن سبب أجنبي لا يدّ له فيه، كحادث مفاجئ أو قوة قاهرة أو خطأ من المضرور أو أو اله 
وينقي الالتزام وفقا للمادة 373 إذا أثبت المدين أن الوفاء به أصبح مستحيلا عليه لسبب أجنبي لا يد لله فيه 15

وقد اتضح أيضا من نص المادة 1218 مدني فرنسي المبينة في السابق أن من بين خصائص الو اقعة التي تثكل القوة القاهرة أنها خارجة عن سيطرة المدين 16.

و الحقيقة أنه إذا كان وجود فيروس كورونا المستجد هو أمر مستقل عن إرادة المدين بالفعل، إلا أن الإصابة به أو نشر العدوى التي قد تتسبب في استحالة تتفيذ العقد، من المكن أن تتنج عن خطأ المدين المتمثل في عدم اتخاذ الاحتياطات اللازمة التي تحول دون انتقال الفيروس أو عدم الالتزام بتدابير مكافحة الفيروس التي أعلنتها الحكومة، ولا يصح الاحتجاج هنا بأن حالة القوة القاهرة تتمثل في المرض؛ ذلك أن المرض لكي يصل إلى مرتبة القوة القاهرة ينبغي أن يتو افر فيه شروط تحققها المعروفة، وهذا هو ما أكدته محكمة النقض الفرنسية في أكثر من مناسبة 17.

="خطأ من الغير، كان غير ملزم بتعويض هذا الضرر، ما لم يوجد نص أو اتفاق على غير ذلك. كما تتص

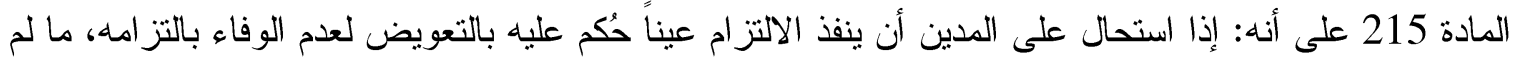

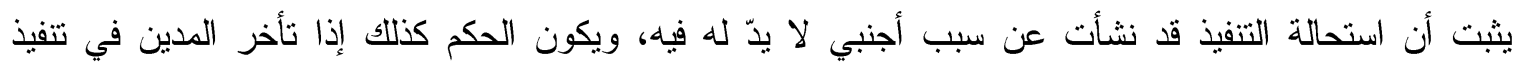

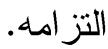
15 تتص المادة 373 مدني مصري على أنه: ينقضي الآلتزام إذا أثبت المدين أن الوفاء به أصبح مستحيلا علبه لسبب أجنبي لا يد له فيه.

${ }^{16}$ Luc Grynbaum, "Force majeure et épidémie de COVID -19", de gaulle fleurance \& Associés (24/03/2020). www.degaullefleurance.com/force-majeure-et-epidemie-decovid-19/ $\cdot(28 / 3 / 2020)$;

Alexandre NIVERT, "Entre COVID-19 et droit commun des contrats : la notion de force majeure", DOCTRIN'ACTU (23/3/2020). https://www.doctrinactu.fr/post/entre-covid19-et-droit-commun-des-contrats-la-notion-de-force-majeure .(28/3/2020).

${ }^{17}$ Cass. 1ère civ. 10 février 1998. $\mathrm{N}^{\circ}$ de pourvoi: 96-13316. Bulletin 1998 I N $53 \mathrm{p}$. 34; 1ère civ., 6 novembre 2002. $\mathrm{N}^{\circ}$ de pourvoi: 99-21203. Bulletin 2002 I No $258 \mathrm{p}$. 201; Cass. 3ème civ. 22 janvier 2014. $\mathrm{N}^{\circ}$ de pourvoi: 12-28246. Bulletin 2014, III, $\mathrm{n}^{\circ}$ 6; Cass. 3ème civ. 19 septembre 2019. $\mathrm{N}^{\circ}$ de pourvoi: 18-18921. 
كما أنه إذا سلمنا بأن القرارات أو التدابير الحكومية التي تتخذها الدولة لمكافحة انتشار الفيروس، والتي تجعل عملية تنفيذ العقد مستحيلة، هي أمر مستقل عن إرادة المدين؛ وبالتالي تشكل قوة قاهرة تتفي مسئوليته 18؛ حيث قضت محكمة استئناف باريس، في هذا الثأن، بأن قرار

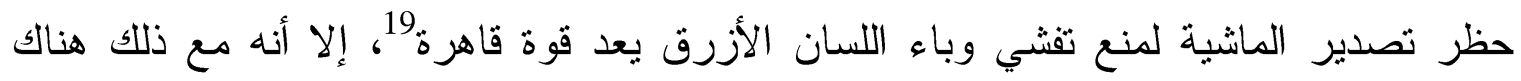
احتمال أن يستدعي المدين بخطئه التدابير أو القرارات الحكومية التي أعجزته عن تتفيذ التزامه، مثال ذلك ما حدث في القضية التي عرضت على محكمة استئناف بو اتييه، و التي تتاولناها أعلاه، و التي احتج فيها المدين بالقوة القاهرة الناتجة عن حجز البضائع في الجمارك، وقد تبين أن ذلك بسبب خطئه كما وضحنا من قبل. و هناك أمتلة عديده على خطأ المدين في هذا السياق ومن ذلك أن يكون المدين صاحب مصنع لم يلتزم بالاحتياطات الصحية للوقاية من الفيروس مما أدى إلى انتشاره بين العمال، و اتخاذ قرار بإغلاق المصنع وعزل المصابين وتعطل عملية الانتاج. كما أنه ينبغي مراعاة شروط تطبيق هذه القرارات، فقد يكون تطبيق مثل هذه القرارات يمنح مساحة معقولة للمدين تسمح له بتتفيذ العقد لكنه مع ذلك يتقاعس ويمتتع عن ذلك؛ وبالتالي ينبغي أن يكون تطبيق القرار الحكومي يجعل من المستحيل تتفيذ العقد كما ذكرنا. وتصلح أيضا العواقب الاقتصادية الناتجة عن الفيرس، والتي تجعل تتفيذ المدين لالتزامه أمر مستحيل، كقوة قاهرة يمكن الاحتجاج بها؛ وهذا هو ما قضت به محكمة استئناف بورج Bourges بشأن فيروس اللسان الأزرق الذي يصيب الماشية؛ فقد اعتبرت العو اقب الاقتصادية الناتجة عنه، على نشاط المدين حدثا لا يمكن مقاومته يبرر تخلفه عن سداد الدين، على أساس أنها

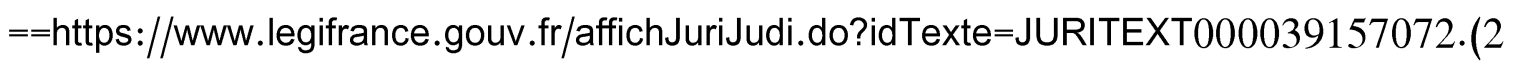
$8 / 3 / 2020)$.

${ }^{18}$ Clément Allais, et.al, "Impacts du Covid-19 en droit administratif,droits de I'homme, droit du travail, droit des contrats et droit penal", NAVACELLE (2020): 19.

http://navacellelaw.com/wpcontent/uploads/NavacelleSynthesedesconsequencesduCovi d-19.pdf. (28/3/2020);

${ }^{19}$ CA Paris, pôle 5 - ch. 4, 26 sept. 2018, n 15/09123. https://www.doctrine.fr/d/CA/Paris/2018/C00ED894B03741A280996 .(15/4/2020). 
قوة قاهرة20. و على الرغم من ذلك إذا كان المدين هو من أحدث تلك العو اقب أو كان سببا في تفاقمها فإنه لا يجوز هنا الاحتجاج بها كقوة قاهرة.

ومن الجدير بالذكر أيضا أنه من المكن أن يكون المدين قد تأخر عن تتفيذ العقد حتى ظهر الفيروس و انتشر في أنحاء البلاد فأصبح تتفيذ العقد أمر مستحيل، هنا لا يحق له الاحتجاج بالقوة القاهرة؛ ذلك أن ميعاد تتفيذ العقد كان قد حل قبل ظهور الفيروس؛ وقضت محكمة النقض المصرية في هذا الثأن بوجه عام بأنه "تعتبر القوة القاهرة من الظروف الطارئة التي تجعل تتفيذ الالتزام مستحيلا وينقضي بها التز ام المدين دون أن يتحمل تبعة عدم تتفيذه ويشترط لذلك أن تكون القوة القاهرة قد حلت خلال الفترة المحددة لتنفيذ الالتز ام، فإذا كانت قد حلت بعد انتهاء تلك الفترة، فإنه لا يسوغ للمدين أن يتمكك بها للتخلص من تبعة عدم تتفيذ التز امه أو التأخير فيه 21. ويمكن أيضا أن يكون خطر الإصـابة بالعدوى قوة قاهرة؛ وقد رأينا ذلك في أحكام محكمة استئناف كولمار التي أشرنا إليها من قبل، إلا أنه يجب تو افر شروط تحقق القوة القاهرة في هذا الثأن، ومن بينها ألا يكون للمدين يد في ذلك.

وجملة القول أنه ينبخي مر اعاة أن هذا الشرط لا يتحقق بصورة تلقائية في كل الحالات التي تتعلق بعدم تتفيذ العقد والتي يزعم فيها المدين بأنها ناتجة عن جائحة فيروس كورونا المستجد، و إنما يجب در اسة كل حالة على حدة بحسب طبيعتها و الظروف و الملابسات المحيطة بها.

${ }^{20}$ CA Bourges, ch. soc., 21 mai 2010, $\mathrm{n}^{\circ}$ 09/01290.

https://www.doctrine.fr/d/CA/Bourges/2010/BF16893DA1B54B44C9576.(15/4/2020);

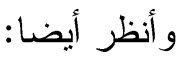

JOAN DRAY, "L'épidémie de coronavirus constitue -il un événement de force majeure ?", legavox blog $(26 / 3 / 2020)$.

https://www.legavox.fr/blog/maitre-joan-dray/epidemie-coronavirus-constitueevenement-force-28444.htm .(15/4/2020).

$$
\text { 21 نقض مدني، طعن رقم } 444 \text { لسنة 44، جلسة 1978/11/27م، مكتب فني، س29، ص } 1766 .
$$




\section{Imprévisible ثانيا: حادث لا يمكن توقعه}

يجب أن يكون الحادث الذي يشكل القوة القاهرة غير ممكن التوقع، وينتفي عنه هذه الصفة إذا كان من الممكن توقعه حتى لو كان من المستحيل دفعه 22. وقد قضت محكمة النقض المصرية في هذا الشأن بأن " المقرر - فى قضاء هذه المحكمة - أنه يشترط لاعتبار الحادث قوة قاهرة عدم إمكان توقعه و استحالة دفعه فإذا تخلف أحد هذين الشرطين انتفت عن الحادث صفة القوة القاهرة و لا يلزم لاعتباره ممكن التوقع أن يقع وفقاً للمألوف من الأمور بل يكفى لذلك أن تشير الظروف و الملابسات إلى احتمال حصوله ولا يشترط أن يكون المدين قد علم بهذه الظروف إذا كانت لا تخفى على شخص شديد اليقظة والتبصر لأن عدم إمكان التوقع اللازم لتوفر القوة القاهرة يجب أن يكون مطلقاً لا نسبياً فالمعيار فى هذه الحالة موضوعى لا ذاتى 23." ويتضح من ذلك أن معيار عدم إمكان التوقع هنا هو معيار موضوعي لا ذاتي، كما أنه لا يُكتفى فيه بالرجوع إلى الثخص العادي ولكن الثخص شديد اليقظة والتبصر ؛ فعم إمكان التوقع ينبغي أن يكون مطلقا وليس نسبيا24.

22

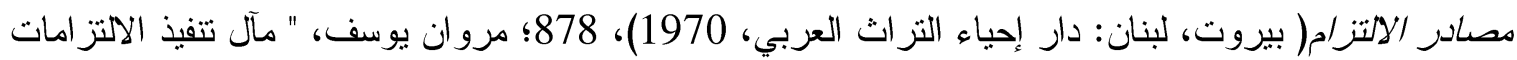
التعاقدية في ظل فيروس كورونا-كوفيد 19-بين إعنباره قوة قاهرة أم ظرف طارىء"، سلسلة إحباء علوم القانون، الدغرب (مايو 2020): 317؛ محمد الأيوبي، " المركز القانوني للمدين في واقعة فيروس "كورونا كوفيد 19" سلسلة إحياء علوم القانون، الدغرب (مايو 2020): 290، 291؛ أمينة رضوان و المصطفى الفوركي، " تأثير فيروس كورونا على الالتزامات التعاقدية"، سلسلة إحباء علوم القانون، الدغرب (مايو 2020): 275؛ محمد الخضراوي، " الآثار القانونية لفيروس كورونا المستجد على الالتزامات التعاقدية"، سلسلة إحياء علوم القانون، الدغرب (مايو 2020): 271؛ عبدالرحيم بحار ، " أثز وباء كورونا المستجد كوفيد 19 على الالتزامات التجارية"، "، سلسلة إحباء علوم القانون، الدغرب (مايو 2020): 387.

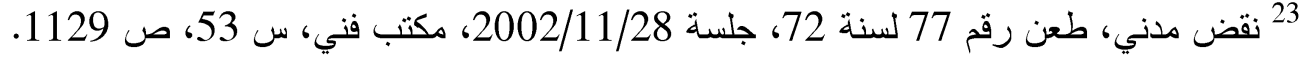
24 السنهوري، الوسيط، 878؛ سمير عبدالسيد تتاغو، مصادر الالتزام (الاسكندرية: مكتبة الوفاء القانونية،

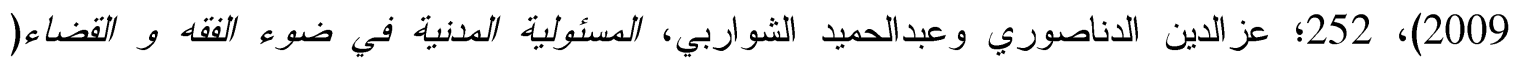
الاسكندرية: منشأة المعارف، 2004)، 225؛ محمد كامل مرسي، شرح القانون المدني الجديد، الجزء الثاني، الالتز/مات(القاهرة: المطبعة العالمية، 1955)، 128؛رمضان أبو السعود، النظرية العامة للالتزام، مصادر الالتزام 
وما سبق ذكره حول معيار عدم القدرة على توقع الحادث، يختلف عما نصت عليه المادة 1218 من القانون المدني الفرنسي في تعريفها للقوة القاهرة؛ حيث نصت المادة الدذكورة على أنه" تتحقق القوة القاهرة في المسائل التعاقدية عند وقوع حادثة خارجة عن سيطرة المدين، لم يكن من المكن توقعها بُكل معقول raisonnablement وقت إبرام العقد.."؛ وهذا يعني أن عدم القدرة على نوقع الحدث هو أمر نسبي وليس مطلق. وقد قنن المشرع الفرنسي ما كان قد توصل إليه الفقه و القضاء في فرنسا فيما يتعلق بهذا الثأن؛ حيث يرى الفقه بأن عدم القدرة على التوقع يقاس بالرجوع إلى معيار المتعاقد المنبصر un contractant prudent، وهو شخص عادي un homme de type moyen يتسم بالحرص والحذر، مع مراعاة المكان و الزمان و الظروف الملابسة للحادث 25، وهناك العديد من الأحكام القضائية تؤيد ذلك 26.

=="(الاسكندرية: دار المطبو عات الجامعية، 2002)، 370؛ نبيل إبراهيم سعد، النظرية العامة للالتزام، مصادر

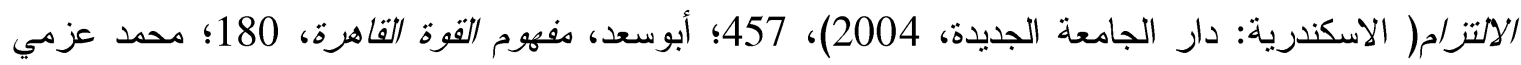
البكري، دعوى التعويض(القاهرة: دار محمود للنشر و التوزيع، 2007)، 85؛ أنظر أيضا في هذا الثأن أحكام محكمة النقض المصرية التاليه: نقض مدني، طعن رقم 677 لسنة 69 ق، جلسة 2012/4/10، مكتب فني، س 63، ص 52/19 589؛ نقض مدني،

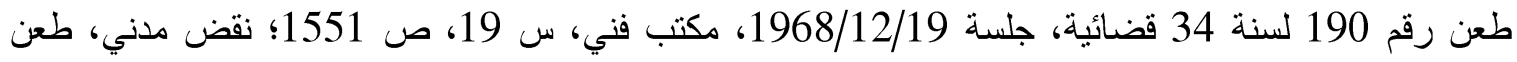
رقم TV09 لسنة 1 1 قضائية، جلسة 2018/4/16، الموقع الرسمي لمحكمة النقض المصرية، عبر هذا الرابط: https://www.cc.gov.eg/judgment_single?id=111379381\&\&ja=225800. (30/3/2020);

نقض تجاري، طعن رقم 77 لسنة 72 قضائية، جلسة 2002/11/28، مكتب فني، س 53، ص 1129. 25 Marie-France STEINLE-FEUERBACH et, al, INONDATIONS: RESPONSABILITES ET FORCE MAJEURE (Colmar, France: Université de Haute-Alsace, 2002), 25, 26; DUMOND, LA DATE ET LE CONTRAT, 111; Assia TOUAHRI, La responsabilité civile du fait du dommage nucléaire civil (thèse de doctorat, UNIVERSITE DE LIMOGES, Faculté de Droit et des Sciences Economiques, 2018), 52; François Chabas, "La force majeure", Dalloz, n 13(septembre 2002): 4, 26.

${ }^{26}$ Cass. 2ème Civ . 22 novembre 1978. $N^{\circ}$ de pourvoi: 77-12767. Bulletin. N. 243 P. 187; cass.3ème Civ. 24 mars 1993. № de pourvoi: 91-13541. Bulletin 1993 III № 46 p. 30; cass.1ère Civ.18 mai 1989. № de pourvoi: 87-16051.Bulletin 1989 I N 205 p. 137; Cass., 2e civ. , 6 juillet 1960. Bulletin. N. 439; Cass.2ème Civ. 5 octobre 1961, 
ونميل إلى أنه ليس هناك خطر لا يمكن توقع حدوثه على الإطلاق؛ و إذا اشترطنا ألا يكون الحادث منوقعا على الإطلاق، فإن هذا يعني أنه من الصعوبة بمكان تحقق القوة القاهرة في الو اقع؛ فكما يقول أندريه نونك André TUNC عن حركة المرور على الطرق" لا يوجد شيء لا يمكن توقعه على الإطلاق. المخاطر موجودة في كل مكان بنسبة معينة. عندما نقول أن تصرف . الغير كان غير منوقع، فإننا نعني أننا لم يكن علينا توقع ذلك، أو بشكل أدق، حتى لو كان بإمكاننا

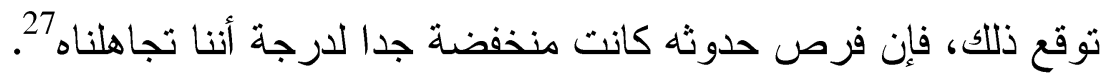

ولذا فإننا نرى أن عدم القدرة على التوقع هو أمر نسبي في هذه الحالة وينبغي أن نرجع فيه إلى معيار الثخص المعتاد لتحديده وقياسه وليس إلى معيار الثخص الأشد يقظة وحرصا، مع هي مر اعاة المكان و الزمان و الظروف الملابسة المحيطة بالحادث.

و الجدير بالذكر أيضا أن الوقت المعتبر فيما يتعلق بعدم القدرة على توقع وقوع الحادث، هو وقت التعاقد، وهذا على خلاف الحال إذا كان الإدعاء بالقوة القاهرة من أجل نفي المسئولية التقصيرية، فالوقت المعتبر هنا هو وقت وقوع الحادث 28.

و إذا حاولنا تطبيق شرط عدم التمكن من توقع الحادث وقت التعاقد، على جائحة فيروس كورونا المستجد، فإن الأمر يثير تساؤلين، الأول: هل وجود أوبئة أو جوائح سابقة يجعل فيروس

$==$ Bull. $n^{\circ}$ 636; Cass. 2ème Civ. 23 octobre 1963. Bull. n659; Cass. 2ème Civ. 30 novembre 1972, Bull. $n^{\circ} 307$.

${ }^{27}$ André Tunc, "Force majeure et absence de faute en matière délictuelle", RTD Civ (1946): 187.

${ }^{28}$ STEINLE-FEUERBACH et, al, INONDATIONS: RESPONSABILITES ET FORCE MAJEURE, 45; TOUAHRI, La responsabilité civile, 53;

$$
\text { ور وراجع أحكام القضاء السنهوري، الفرنسي: }
$$

cass.1ère Civ.18 mai 1989. № de pourvoi: 87-16051. Bulletin 1989 I No 205. 137; cass., 1ère Civ. 4 février 1997, $\mathrm{N}^{\circ}$ de pourvoi: 94-22-203. 
كورونا المستجد من الأمور التي كان يمكن توقعها من جانب المدين، وماذا لو كان الفيروس السابق مشابها لفيروس كورونا المستجد، وهل تكرار انتشار نفس الفيروس يجعله أمرا منوقعا أيضا؟ والثاني: ما هو الوقت المعتبر في إعتبار فيروس كورونا المستجد أمر منوقعا؟

وبالنسبة للتساؤل الأول فان وجود أوبئة أو جوائح سابقة لا يعني أنه كان على المدين نوقع ظهور فيروس كورونا المستجد وانتشاره؛؛ ذلك أن الفيروسات تختلف فيما بينها من حيث مخاطرها وطرق مكافحتها وتأثثرها بوجه عام على حياة الإنسان، كما لا يمكن تحديد وقت ظهورها واختفائها بصورة دقيقة مسبقا30. و لا ينفي ذلك وجود تشابه بين كورونا المستجد (SARS-CoV-2) ومتلازمة الالتهاب الرئوي الحاد الوخيم "سارس" (SARS-CoV) الذي انتشر في 2003؛ فعلى الرغم من أن هناك إرتباط جيني بين الفيروسين إلا أن هناك أيضا

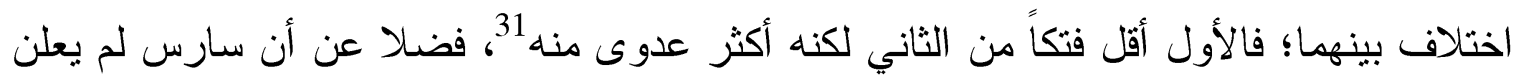
كجائحة من قبل منظمة الصحة العالمية مثلما حدث بشأن كورونا المستجد.

أما مسألة نكر ار ظهور الفيروس وهل يعني ظهور فيروس معين في السابق أن يكون على المدين توقع ظهوره في المستقبل؛ بحيث إذا ظهر مجددا لا يكون من حق المدين الإحتجاج به كقوة قاهرة لنفي مسئوليته التعاقدية؛ فقد قضت محكمة استئناف نانسي في 22 نوفمبر 2010 بأن

${ }^{29}$ Xavier Azaïs, CORONAVIRUS (COVID-19) : FAUT-IL PRÉFÉRER L'IMPRÉVISION À LA FORCE MAJEURE ?", village de la justice (19 MARS 2020). https://www.villagejustice.com/articles/coronavirus-covid-faut-preferer-imprevision-forcemajeure,34184.html. (30/3/2020).

30 راجع هذا المعنى لدى: منظمة الصحة العالمية(المكتب الإقليمي للشرق الأوسط)، أسئلة وأجوبة حول فيروس كورونا المستجد، من خلال هذا الر ابط: لكني http://www.emro.who.int/ar/health-topics/corona-virus/questions-and-answers.html. (30/3/2020).

31 راجع: منظمة الصحة العالمية، مرض فيروس كورونا (كوفيد-19): أسئلة وأجوبة، من خلال هذا الر ابط: https://www.who.int/ar/emergencies/diseases/novel-coronavirus-2019/advice-forpublic/q-a-coronaviruses.(30/3/2020). 
فيروس حمى الضنك لا يملك خصائص القوة القاهرة؛ لأنه مرض مستوطن Endémie في جزيرة مارتينيك Martinique، أي أنه يتكرر في هذه المنطقة، وبالتالي يمكن نوقعه، كما أنه يمكن مقاو مته بالوسائل المتاحة.32

وقضت أيضا محكمة استئناف باسي تيري Basse Terre في 17 ديسمبر 2018، بأن فيروس الثيكونغونيا chikungunya لا يمكن اعتباره غير منوقع أو لا يمكن مقاومته؛ ذلك أنه من الأمر اض المعروفة في المنطقة ويمكن علاجه بالأدوية.33.

ومع ذلك قضت محكمة أستئناف أيكس أون بروفانس Aix en Provence في 3 ما يو

2006، بعدم مسئولية كلا من صاحب فندق ووكالة سفر عن إغلاق نادي الطفل و إصابة اثثين من العملاء بفيروس التهاب المعدة والإمعاء la gastroentérite، تأسيسا على القوة القاهرة؛ لأنه لم يكن في إمكانها نوقع نطاق هذا الفيروس، على الرغم من أنه عدوى شائعة.34.

${ }^{32}$ CA Nancy, 1re ch., 22 nov. 2010, n09/00003.

https://www.doctrine.fr/d/CA/Nancy/2010/B81811A63DBC13171C555 .(15/4/2020);

وأنظر أيضا:

Pascale Guiomard, "La grippe, les épidémies et la force majeure en dix arrêts", dalloz (4/3/2020). https://www.dalloz-actualite.fr/flash/grippe-epidemies-et-force-majeureen-dix-arrets\#.Xs_uwzozblU.$(15 / 4 / 2020)$.

${ }^{33}$ CA Basse-Terre, 1re ch., 17 déc. 2018, n 17/00739.

https://www.doctrine.fr/d/CA/Basse-Terre/2018/C7C3F833356E1904494E4 .$(15 / 4 / 2020)$;

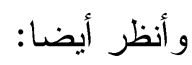

CÉLINE MOILLE, "Force majeure et Covid-19 : une notion simple à invoquer en matière contractuelle ?", WOLTERS KLUWER FRANCE (25/3/2020).

https://www.actualitesdudroit.fr/browse/civil/contrat/26561/force-majeure-et-covid-19une-notion-simple-a-invoquer-en-matiere-contractuelle $\cdot(15 / 4 / 2020)$.

${ }^{34}$ CA Aix-en-Provence, 3 mai 2006, JurisData n²006-306944; 
و الحقيقة أنه كما هو معروف أن فيروس كورونا (SARS-CoV-2) هو فيروس مستجد لم يكن معروف قبل انتشاره في مدينة ووهان الصينية في ديسمبر 2019، وفقا لما بينته منظمة

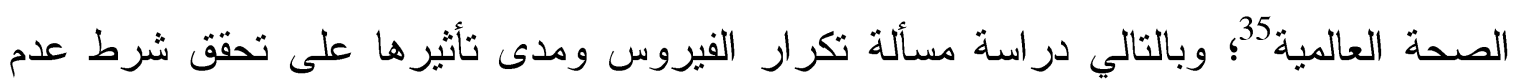
التوقع، المنطلب لقيام القوة القاهرة، ليست لها أهية الآن، لكنها مفيدة من ناحيتين، الأولى: إذا ما تكرر انتشار فيروس كورونا المستجد في المستقبل مرة أخرى. وأما الثانية: فهي لمعرفة مدى تحقق شرط عدم التوقع بخصوص الفيروسات الأخرى التي تكرر انتشارها. وفي كلتا الحالتين فإننا نرى أنه لا يمنع تكرار الفيروس من الاحتجاج به كقوة قاهرة إذا وصل إلى نطاق أو شدة لم يكن بالإمكان توقعها وقت التعاقد، وكذلك أيضا إذا كان نادر ا بحيث لا يوجد سبب خاص لتوقع حدوثه وقت التعاقد، كما يذهب بعض الفقه

وفيما يتعلق بالتساؤل الثاني الذي عرضناه أعلاه والخاص بالوقت الذي يعد الفيروس فيه أمر ا متوقعا؛ فإننا نعني الوقت الذي لا يمكن للمدين في العقود المبرمة بعده الاحتجاج بالفيروس كقوة قاهرة. ويرى البعض في هذا الثأن أنه منذ الإعلان عن وجود الفيروس، لا يصح الاحتجاج به كقوة قاهرة لأنه أصبح أمرا منوقعا37. وقضت محكمة استئناف سانت دينيس بأن وباء

==ZAN Daouda, "L'IMPACT DU CORONAVIRUS(COVID-19) SUR LE CONTRAT DE TRAVAIL", Revue Juridique du Faso (31/3/2020).

https://revuejuris.net/2020/03/31/limpact-du-coronaviruscovid-19-sur-le-contrat-detravail/ $\cdot(15 / 4 / 2020)$.

35 راجع: منظمة الصحة العالمية، مرض فيروس كورونا (كوفيد-19): أسئلة وأجوبة، من خلال هذا الر ابط: https://www.who.int/ar/emergencies/diseases/novel-coronavirus-2019/advice-forpublic/q-a-coronaviruses.(30/3/2020).

$$
\text { 37 36 راجع: السنهوري، الوسيط، 878؛ الدناصوري و الثو اربي، الدسئولية الدننية ، } 225 .
$$

Ludovic Landivaux, "Contrats et coronavirus : un cas de force majeure ? Ça dépend...", Dalloz (20 mars 2020). https://www.dalloz-actualite.fr/node/contrats-et-coronavirusun-cas-de-force-majeure-ca-depend\#.XqIOpY9OLIU.(29/3/2020): MEDEF, 'L'impact 
الثيكونغونيا الذي بدأ في يناير 2006 لا ييرر إنهاء العقد في أغسطس التالي بعد التعاقد في 4

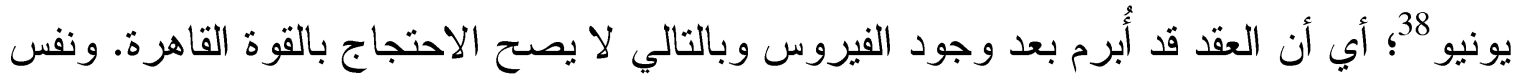
الثىء أيضا لم تعتبر محكمة استئناف بيزنسون فيروس إنفلونزا الخنازير H1N1 قوة قاهرة لأنه كان منوقعا وقت النعاقد بسبب الإعلانات التي صدرث بهذا الثأن حتى قبل تتفيذ التدابير الصحية

ومن وجهة نظرنا أن الإعلان عن الفيروس لا يصلح ضابطاً في هذا الثأن وذلك لثثلاثة

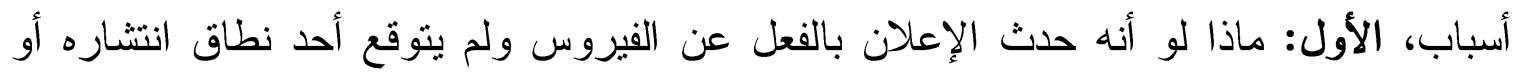

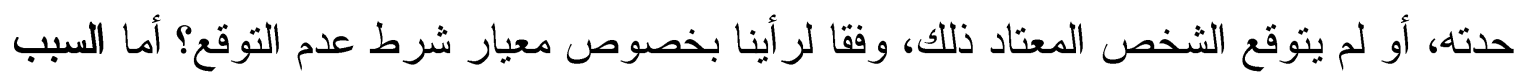

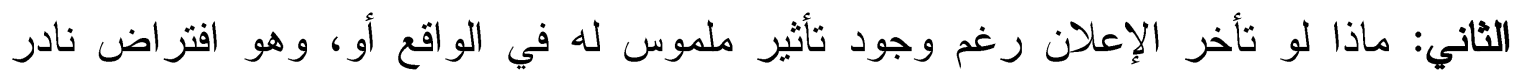

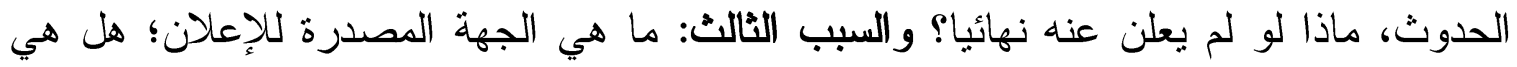

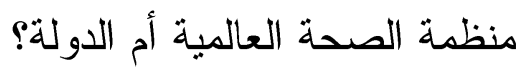
وبالنسبة للسبب الأول المذكور أعلاه، فإنه يدور حول عدم توقع نطاق انتشار الفيروس أو

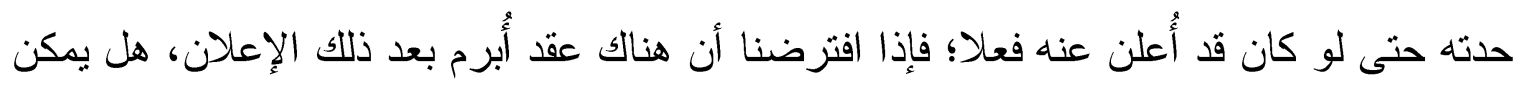
للمدين بالالتزام الناشىء عنه، الاحتجاج بالفيروس كقوة قاهرة لنفي مسئوليته عن عدم التتفيذ،

$==\mathrm{du}$ Covid -19 dans les relations contractuelles", aacc, (10 mars 2020): 1 . http://www.aacc.fr/uploads/file/file/000/000/770/12601-medef-impact-du-covid-19dans-les-relations-contractuelles.pdf. (29/3/2020); Benjamin Balensi et GisèleAimée Milandou, "Coronavirus : quel usage de la force majeure dans les contrats commerciaux ?", taj, (24 mars 2020). https://taj-strategie.fr/coronavirus-usage-deforce-majeure-contrats-commerciaux. (29/3/2020); Azaïs, "CORONAVIRUS (COVID19).

38 CA Saint-Denis de la Réunion, ch. soc., 29 déc. 2009, nº 08/02114.

https://www.doctrine.fr/d/CA/SaintDenis_de_la_Reunion/2009/SK70FA78F144D2A1EB EFDC $\cdot(15 / 4 / 2020)$.

${ }^{39}$ CA Besançon, 2 ème Chambre commerciale, 8 janvier 2014, RG nº 12/02291. 
على أساس أنه لم يتوقع نطاق انتشاره أو حدته؟ و الحقيقة أنه يصح ذلك؛ فكما ذكرنا أعلاه أن محكمة أستثناف أيكس أون بروفانس Aix en Provence قضت بعدم مسئولية كلا من صاحب الفندق ووكالة السفر لأنه لم يكن بإمكانهما توقع نطاق انتشار فيروس التهاب المعدة والأمعاء على ترى الرغم من أنه مرض شائع؛ وهذا يعني أنهما لم ينوقعا ضر اوته وشدته. وقد قضت أيضا محكمة النقض المصرية بأن "مخاطر البحر وإن كانت تصلح فى ذاتها سببا اتفاقيا للإعفاء من المسئولية ولو كانت متوقعة الحدوث أو يمكن دفعها، إلا أن هذه المخاطر إذا بلغت من الثدة مدى يجعلها غير متوقعة الحدوث أو غير مستطاع دفعها فإنها تعد من قبيل القوة القاهرة التى تصلح سببا قانونيا للإعفاء"40. ونرى أن ذلك لا يصلح للتطبيق فقط على حالة التعاقد بعد الإعلان عن الفيروس الذي لم يتوقع المدين نطاق انتشاره وحدته، بل يصلح ذلك للنطبيق أيضا على كل حالات تكرار الفيروس؛ فلو أن هناك فيروس ظهر لمدة واختفى أو نم القضاء عليه ثم ظهر بعد فترة من جديد، فإنه من الممكن أن يكون قوة قاهرة إذا كان نطاق انتشاره أو شدته غير منوقعه أو كان نادر ا بحيث لم يكن هناك سبب خاص لتوقع وقو عه، وقد وضحنا ذلك أعلاه.

أما بالنسبة للسبب الثاني فإنه يدور حول حكم العقود التي تبرم بعد وجود تأثير للفيروس في الواقع على حياة الإنسان الطبيعية، بما في ذلك تتفيذ الالتزامات المدنية، في حين لم يتم الإعلان عنه، سواء جاء الإعلان بعد ذلك أم لم يعلن نهائيا عنه، وهو فرض نادر الحدوث كما قلنا. و الحقيقة أنه لا يشترط أن يتم الإعلان عن الفيروس لكي يصير أمرا منوقعا؛ فلو أن هناك ما يشير إلى وجوده أو بمعنى أدق ما يشير إلى ضرورة مواجهته من خلال التدابير الاحتر ازية و الوقائية المعروفة، بصورة لا تخفى على الثخص المعتاد، بحسب رائنا، أو شخص شديد اليقظة و التبصر ، بحسب اتجاه محكمة النقض المصرية، فإنه يصبح أمر ا منوقعا.

وبالنسبة للسبب الثالث فإنه يثير مسألة تحديد الجهة الني يعد إعلانها عن وجود الفيروس سببا في نفي عدم القدرة على توقعه وبالتالي عدم اعتباره قوة قاهرة؛ فهل هي منظمة الصحة العالمية،

40 نقض مدني، طعن رقم 272 لسنة 31، جلسة 17 من مايو سنة 1966، المكتب الفني، س 17، ص 1129. 
كما يذهب البعض 4 أم الدولة كما يذهب البعض الآخر 42، و إذا كانت الجهة هي منظمة الصحة العالمية فهل نعتد بتاريخ اعلانها عن وجود الفيروس أم إعلانها له كحالة طواريء صحية عامة أم كجائحة، و إذا كانت الجهة هي الدولة؛ فهل هي الدولة التي يحمل المدين جنسيتها أو الدولة التي يقيم فيها أم هي الدولة التي سينفذ فيها العقد، وماذا لو كان يعتمد على مواد خام من دول أخرى أو هي هـي عدة دول لتنفيذ الالتزام المطلوب، وهل يمكن التعويل على الإعلان عن الفيروس الصادر من وسائل الإعلام المختلفة وليس الجهات الرسمية. وأمام كل هذه التساؤلات فإننا نرى أنه ينبغي النظر في كل حالة على حدة مع الأخذ في الاعتبار ما كان يتوقعه الثخص المعتاد كما قلنا أعلاه؛ أي بالرجوع إلى المعيار السابق شرحه وبذلك نكون في غنى عن بحث الإجابة عن التساؤلات

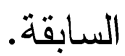

وسواء كان الحدث الذي يحتج به المدين كقوة قاهرة منعته من تتفيذ التزامه، يتمثل في إصابته بالفيروس أو مجرد خطر العدوى به أو التدابير الحكومية التي تتذذها الدولة لمواجهته أو لو لهوه العو اقب الاقتصادية الناتجة عنه، فإنه في كل هذه الحالات يجب أن ينو افر شرط عدم القدرة على بلى بلى التوقع لتحقق القوة القاهرة، وفقا للنهج الذي اتبعناه بخصوص هذا الحالات عند شرحنا للشرط الأول، وفي ضوء النطبيقات القضائية التي ذكرناها في هذا الثأن.

${ }^{41}$ Azaïs, "CORONAVIRUS (COVID-19) : FAUT-IL PRÉFÉRER L'IMPRÉVISION À LA FORCE MAJEURE ?".

${ }^{42}$ Valérie Ledoux, "Coronavirus et (in)exécution des contrats d'affaires", racine avocats (2 Avril 2020): 2. https://www.racine.eu/wp-content/uploads/2020/04/coronavirus-etinexecution-du-contrat-daffaires-02042020-2.pdf.( 30/3/2020). 


\section{Irrésistible ثالثا: حادث لا يمكن مقاومته}

ينبغي أن يكون الحادث الذي يزعم المدين بأنه قوة قاهرة، غير ممكن دفعه و تجنبه؛ بحيث إذا كان في الإمكان مقاومته وبالتالي يتحقق بذلك تتفيذ الالتزام على الوجه المطلوب، فإنه لا يشكل قوة قاهرة، حتى لو كان من المستحيل نوقعه وقت التعاقد ${ }^{43}$ وعدم القدرة على دفع الحدث تعني أن المدين لم يكن لديه القدرة على منع وقو عه أو تلاشيه، أما عدم قدرة المدين على تجنب الحدث

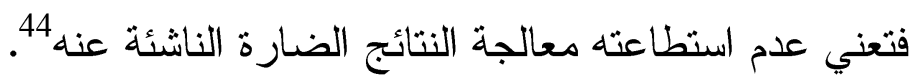

وتقدير نوافر عدم القدرة على مقاومة الحدث، وفقا للعديد من أحكام محكمة النقض المصرية، يكون بمعيار موضوعي لا ذاتي، أي لا عبرة فيه بشخص المدين وظروفه الخاصة، كما لا يعتد فيه، مثل تقدير عدم القدرة على التوقع، بمعيار الثخص المعتاد و إنما بمعيار أثند

43 STEINLE-FEUERBACH et, al, INONDATIONS: RESPONSABILITES ET FORCE MAJEURE, 29; Jacques Moury, "Force majeure éloge de la sobriété", RTDciv : Revue Trimestrielle de droit civil, № 3 (2004): 471. https://halshs.archives-ouvertes.fr/halshs02247568.(30/3/2020); Patrice Jourdain. Force majeure : I'Assemblée plénière manque I'occasion d'une définition claire. Recueil Dalloz, (2006): 1577. https://actu.dallozetudiant.fr/fileadmin/actualites/pdfs/Juillet/D2006-1577.pdf.(30/3/2020);

Patrice Jourdain, "Le rôle de l'imprévisibilité de la cause étrangère", RTD Civ (1994): 871.https://actu.dallozetudiant.fr/fileadmin/actualites/pdfs/04._2017/rtd_civ_1994_871. pdf.(30/3/2020);

$$
\text { وراجع أيضا: السنهوري، الوسيط، } 879 .
$$

44 أنظر هذا المعنى لاى: شريف محمد غنام، أثر تغير الظروف في عقود التجارة الدولية ( دبي، الإمارات

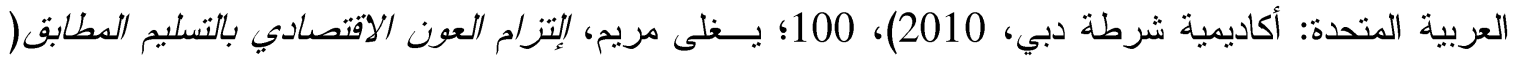

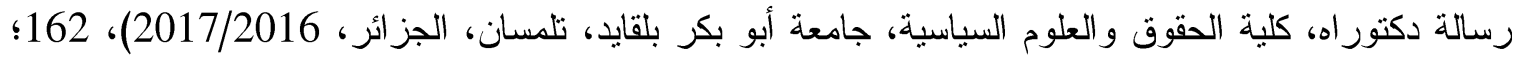

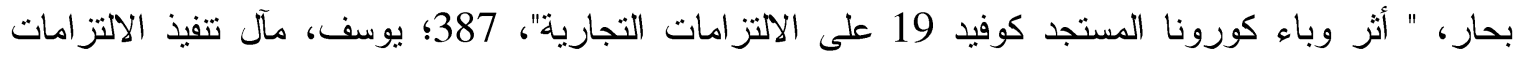

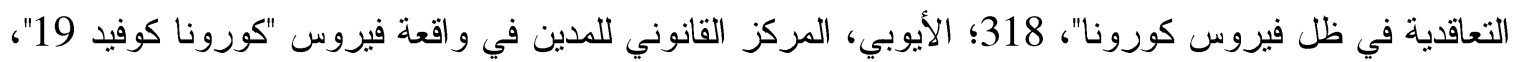


الناس يقظة وبصر ا بالأمور؛ فينبغي أن يستحيل على المدين مقاومة الحدث بصورة مطلقة لا نسبية 45 ويتضح من نص المادة 1218 مدني فرنسي، التي ذكرناها من قبل، أن الحادث الذي تتحقق به القوة القاهرة ينبغي أيضا ألا يكون في الإمكان تجنب آثاره باتخاذ إجر اءات مناسبة، ويفهر من هذه المادة أن عدم إمكان مقاومة الحدث ليس مطلقا و إنما نسبيا، وهو ما ير اه الفقه الفرنسي وتؤيده العديد من أحكام محكمة النقض الفرنسية أيضا؛ حيث إن تقدير هذا الأمر يكون بالرجوع إلى معيار الثخص العادي الذي يوضع في نفس الظروف 46.

$$
\text { 45 نقض مدني، الطعن رقم } 15480 \text { لسنة } 83 \text { قضائية، جلسة 2019/6/15. }
$$

https://www.cc.gov.eg/judgment_single?id=111392766\&\&ja=265979 $\cdot(1 / 4 / 2020)$; نقض مدني، الطعن رقم 18466 لسنة 83 قضائية، جلسة 2019/3/24. https://www.cc.gov.eg/judgment_single?id=111391071\&\&ja=260532.$(1 / 4 / 2020)$;

$$
\text { نقض مدني، الطعن رقم } 7627 \text { لسنة } 82 \text { قضائية، جلسة 201/4/2/18. }
$$
https://www.cc.gov.eg/judgment_single?id=111391429\&\&ja=261244.$(1 / 4 / 2019)$.

$$
\text { نقض مدني، الطعن رقم } 7325 \text { لسنة } 81 \text { قضائية، جلسة 1/4/2019). 2018/11/19. }
$$
https://www.cc.gov.eg/judgment_single?id=111388866\&\&ja=255800 $\cdot(1 / 4 / 2019)$.

نقض مدني، الطعن رقم 13404 لسنة 81 قضائية، جلسة 1/4/2018/10/1. https://www.cc.gov.eg/judgment_single?id=111389012\&\&ja=255969.$(1 / 4 / 2020)$;

$$
\text { نقض مدني، الطعن رقم } 300 \text { لسنة } 80 \text { قضائية، 1/4/2020). }
$$

https://www.cc.gov.eg/judgment_single?id=111388751\&\&ja=224809.$(1 / 4 / 2020)$;

نقض مدني، الطعن رقم 5125 لسنة 81 قضائية، جلسة 2018/6/24. https://www.cc.gov.eg/judgment_single?id=111386054\&\&ja=255225 $\cdot(1 / 4 / 2020)$; وراجع أيضا معيار عدم إمكان مقاومة الحدث، وكون أن استحالة المقاومة يجب أن تكون مطلقة وليست نسبية:

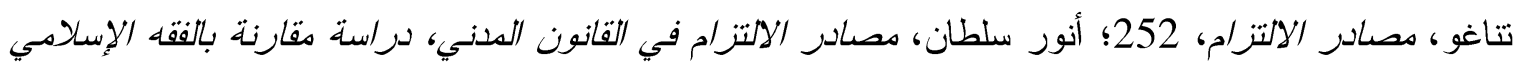

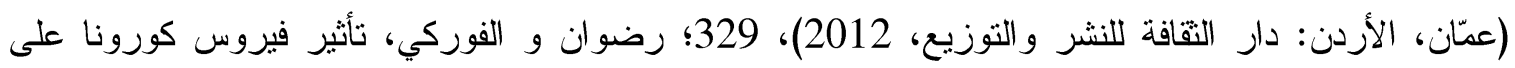

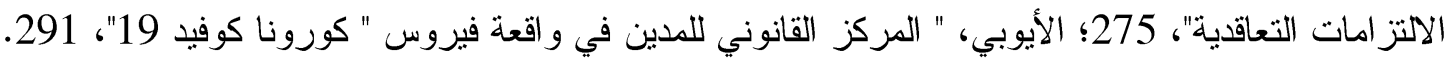
${ }^{46}$ Léon Mazeaud et Henri Mazeaud, Traité théorique et pratique de la responsabilité civile, délictuelle et contractuelle, tome 2 (Paris: Librairie du Recueil Sirey, société anonyme, 1934), $\mathrm{n}^{\circ}$ 1572; Marcel Planiol et Georges Ripert, Traité pratique de droit 
ونرى أنه يُكتفى في تقدير انعدام القدرة على مقاومة الحدث بالرجوع إلى معيار الثخص المعتاد؛ ذلك أن الاعتماد على دعيار الثخص شديد اليقظة والتبصر ، سيعل على تضييق نطاق تطبيق نظرية القوة القاهرة بصورة كبيرة.47. وهناك العديد من الأحكام الصادرة عن القضاء الفرنسي تتناول تطبيق شرط عدم إمكانية مقاومة الحدث على فيروسات ظهرت في الماضي؛ فقد قضت محكمة إستئناف أجان بأن وباء البروسيلات البقري épidémie de brucellose bovine يستجمع خصائص القوة القاهرة؛ فهو ينتشر بسهولة ومعد بشكل كبير لأنه ينتقل عبر أي ناقل، مثل لدغات الحشرات أو جسم الإنسان، ويتسم بفترة خمول une période de latence لا يمكن اكتشافها أو التتبؤ بها 48. وقد بينت أيضا محكمة استئناف باريس في حكمها الصادر في تاريخ 26 سبتمبر 2018م بأن la القيود الحدودية المفروضة من جانب السلطات الصحية لاحتو اء تقشي وباء اللسان الأزرق

$==$ civil français tome 7, 2ème edition (Paris: Librairie générale de droit et de jurisprudence, 1931), n' 839; DUMOND, LA DATE ET LE CONTRAT, 112; TOUAHRI, La responsabilité civile du fait du dommage nucléaire civil, 54; Pierre Moisan, "Technique contractuelle et gestion des risques dans les contrats internationaux : les cas de force majeure et d'imprévision", Les Cahiers de droit 35, n² 2(1994): 291. https://core.ac.uk/download/pdf/59347623.pdf. (5/5/2020).

وراجع أيضا أحكام محكمة النقض الفرنسية النالية:

Cass. 2ème Civ.6 juillet 1960, Bull., n' 439.

Cass. 2ème Civ. 6 avril 1965, Bull., n' 355.

47 للمزيد من التفاصيل حول الاتجاه الموضوعي في تقدير عدم القدرة على مقاومة الحدث وكذلك عدم إمكان

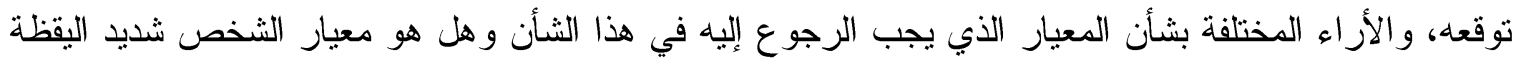

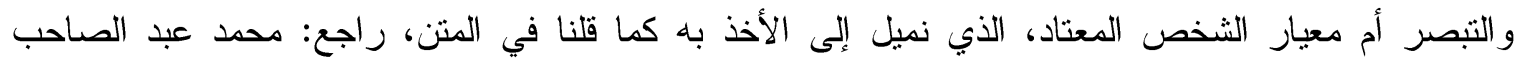

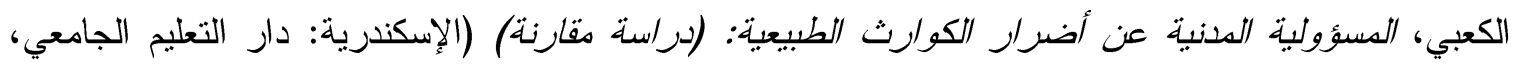
.113-107،( 2019

${ }^{48}$ CA Agen, 21 janvier 1993, JurisData $n^{\circ} 1993-040559$. 
langue bleue تمنع تتفيذ العقد وقت الأزمة الصحية.49.

وقضت أيضا محكمة استئناف بورج Bourges في تاريخ 21 مايو 2010 بأن وباء اللسان الأزرق الذي يصيب الماشية كان له عواقب إقتصادية على نشاط المدين لم يكن في الإمكان مقاومنها، تبرر التخلف عن السداد، كونها قوة قاهرة.50.

و على العكس من ذلك قضت محكمة استئناف باسي تيري، في قضية ذكرناها سابقا، تتعلق بإلغاء الحجز الفندقي بسبب وباء الثيكونغونيا، بأن الوباء الدذكور لا يستجمع خصائص القوة القاهرة؛ فهو لم يكن الحدث الذي لا يمكن التنبؤ به و لا يمكن مقاومته على وجه الخصوص؛ لأنه في كل الأحو ال يمكن التغلب عليه بتتاول بعض المسكنات؛ حيث إن المستأنف ضدهم لم يبلغوا عن أي ضعف أو هشاشة طبية معينة تتعلق بهم 51.

وقضت أيضا محكمة إستئناف نولوز في 3 أكتوبر 2019 بأن تأثير تدابير الاحنواء la grippe aviaire المطبقة لمنع تفشي فيروس إنفلونز الطيور mesures de confinement (H5N1)

${ }^{49}$ CA Paris, pôle 5 - ch. 4, 26 sept. 2018, n 15/09123.

https://www.doctrine.fr/d/CA/Paris/2018/C00ED894B03741A280996 .(15/4/2020).

${ }^{50}$ CA Bourges, ch. soc., 21 mai 2010, n 09/01290.

https://www.doctrine.fr/d/CA/Bourges/2010/BF16893DA1B54B44C9576 .(15/4/2020);

و أنظر أيضا:

Philippe JULIEN, "Coronavirus (Covid-19) : faut-il payer les loyers commerciaux du 2e trimestre 2020 ?", Editions Francis Lefebvre (19/3/2020).

https://www.efl.fr/actualites/affaires/biens-de-l-entreprise/details.html?ref=fe6303cfb7204-49e7-ab1b-98432000f5a5 .(15/4/2020); Romain Rossi-Landi, "Non-paiement des loyers : ce que prévoit le droit pour les baux commerciaux, BFM Immo (25/3/2020). http://rossi-landiavocat.fr/2020/03/25/non-paiement-des-loyers-ceque-prevoit-le-droit-pour-les-baux-commerciaux/ .(15/4/2020).

${ }^{51}$ CA Basse-Terre, 17 décembre 2018, RG n¹7/00739. 
يُظهر أن لها طابعا لا يقاوم أو لا يمكن التغلب عليه ئه caractère insurmontable et يمكن أن يجعلها قوة قاهرة تبرر عدم دفع إيجار المزرعة لئ.52 ئ.

وقضت محكمة استئناف نانسي في 22 نوفمبر عام 2010 بأن وباء حمى الضنك في جزر

المارتينيك لا يعد قوة قاهرة؛ ذلك أنه يمكن توقعه نظر التكراره فهو من الأمر اض المنوطنه في المنطقة، وقد قلنا ذلك أثناء شرحنا للشرط السابق، كما أنه يمكن مقاومته بالوسائل المتاحة؛ فضلا عن أن معدل انتشاره منخفض و عدد الحالات التي حدث لها مضاعفات قليل أيضاك.53.

أما بالنسبة لجائحة فيروس كورونا (كوفيد-19)، فكما وضحنا أثناء شرحنا للشرط الأول من شروط تطبيق القوة القاهرة، أن محكمة استئناف كولمار اعتبرت أن الظروف الاستثنائية الناتجة عن مخاطر العدوى بالفيروس، تستجمع خصائص القوة القاهرة المعروفة؛ كونها خارجية، لا يمكن التتبؤ بها و لا يمكن مقاومتها، و تبرر عدم حضور جلسات المحكمة، وظهر ذلك في الأحكام الصادرة عن المحكمة في أكثر من مناسبة، كما وضحنا سابقات

${ }^{52}$ CA Toulouse, 3 e ch., 3 oct. 2019, n 19/01579. https://www.doctrine.fr/d/CA/Toulouse/2019/C50319E5E954A0498D5C1. (15/4/2020); وراجع أيضا في هذا الثأن: Me Clément DIAZ, "Le Covid19 constitue-t-il un cas de force majeure pouvant justifier I'inexécution d'une obligation contractuelle ?", Avocat.fr, Blog des avocats, Blog de Me Clément DIAZ (27/5/2020). https://consultation.avocat.fr/blog/clement-diaz/article35228-le-covid19-constitue-t-il-un-cas-de-force-majeure-pouvant-justifier-Iinexecution-d-une-obligation-contractuelle.html .(29/5/2020);

Didier DOMAT, Neal LACHMANY et Alexandre DANION, "Les contrats de sponsoring des clubs sportifs à l'épreuve de l'épidémie de covid-19", doctrine actu $(21 / 4 / 2020)$. https://www.doctrinactu.fr/post/les-contrats-de-sponsoring-des-clubs-sportifs-a-l\%C3\%A9preuve-de-I-\%C3\%A9pid\%C3\%A9mie-de-covid-19 • (29/5/2020).

${ }^{53}$ CA Nancy, 1re Chambre civile, 22 novembre 2010, RG nº 09/00003. 
ونرى أن النظر إلى فيروس كورونا المستجد من زاوية مدى إمكانية مقاومته، لا ينفصل عن حقيقة هذا الفيروس والخصائص التي يتسم بها؛ فوفقا لمنظمة الصحة العالمية، ليس هناك علاج للمصابين بهذا الفيروس حتى الآن أو لقاح للوقاية منه، كما أنه سريع الانتشار؛ فقد تفشى في العالم في وقت قصبر، للدرجة التي كانت سببا في إعلانه كجائحة من قبل المنظمة؛ وقد ساعد على ذلك طول فتزة حضانته التي قد تصل إلى 14 يوما؛ في حين أنه قد لا تظهر أية أعر اض على المصاب خلال هذه المدة أو تظهر عليه مجرد أعراض خفيفة، وبالتالي يمكن أن يكون الثخص سبيا في نقل الفيروس لغيره دون أن يعلم، كما أنه فيروس مستجد ماز ال الكثير عنه مجهول بالنسبة للباحثين 55.

وعلى الرغم مما سبق فإنه لا يصح القول بأن جائحة فيروس كورونا المستجد نشكل قوة

قاهرة في كل الحالات بصورة تلقائية، بل بتعين على القضاء أن بنظر في كل حالة على حدة لكي يتضح مدى استجابة كل حالة لشروط تحقق القوة القاهرة، ومن بينها شرط عدم القدرة على مقاومة الفيروس أو آثارهـ56.

==Luc Grynbaumm, "Force majeure et épidémie de COVID -19 : une première décision vient d'être rendue", le club des jurists (25 mars 2020). https://www.leclubdesjuristes.com/blog-du-coronavirus/que-dit-le-droit/force-majeureet-epidemie-de-covid-19-les-premieres-decisions-viennent-detre-rendues/. $(20 / 5 / 2020)$.

$$
55 \text { راجع: منظمة الصحة العالمية، "مرض فيروس كورونا (كوفيد-19)"، من خلال هذا الر ابط: }
$$
https://www.who.int/ar/emergencies/diseases/novel-coronavirus-2019/advice-forpublic/q-a-coronaviruses $\cdot(10 / 5 / 2020)$;

ور اجع أيضا: الصفحة الخاصة بجائحة كورونا(كوفيد-19)، على موقع منظمة الصحة العالمية، من خلال هذا الر ابط:

https://www.who.int/ar/emergencies/diseases/novel-coronavirus-2019 •(10/5/2020). ور اجع أيضا: شبكة معلومات منظمة الصحة العالمية عن الأوبئة، من خلال هذا الر ابط: https://www.who.int/epi-win .(10/5/2020). 
وكما أشرنا أثناء شرحنا للشرطين السابقين أنه يمكن أن تتمثل القوة القاهرة بشأن جائحة فيروس كورونا في الإصابة بالفيروس أو مجرد خطر العدوى به أو التدابير الحكومية التي

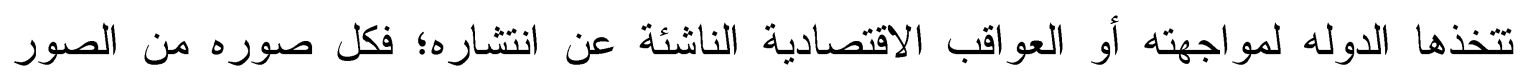
الأربع المذكورة يمكن أن تمنع المدين من تتفيذ التزامه على الوجه المطلوب. وبالنسبة للإصابة بالفيروس، فقد وضحنا أثناء شرحنا للشرط الأول أن محكمة النقض الفرنسية في أكثر مناسبة اشترطت لكي يحتج بالمرض كقوة قاهرة أن يتو افر فيه شروط تحقق القوة القاهرة المعروفة، ومن

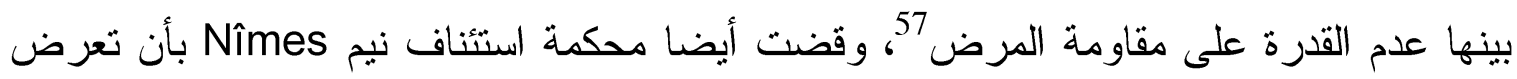
المحامي للوهن العضلي الثديد asthénie بصورة مفاجئة وغير متوقعة، مما تحتم معاه، بصورة لا تقاوم، دخوله إلى المستشفى، يعد قوة قاهرة يترتب عليها عدم تطبيق الجزاء المنصوص عليه في حالة عدم الالتز ام بالمو عد الإجر ائي 58.

$==$ Avocats mathias, "Covid-19 : un cas de force majeure ?", avocats-mathias (20 mars 2020).

https://www.avocats-mathias.com/actualites/force-majeure-impacts-contrat .(20/5/2020);

Philippe Bensussan, "Le sort des loyers en matière de bail commercial à l'épreuve du COVID-19", LE MONDE DU DROIT (2 AVRIL 2020). https://www.lemondedudroit.fr/decryptages/69198-sort-loyers-bail-commercialcovid19-coronavirus.html $\cdot(20 / 5 / 2020)$.

${ }^{57}$ Philippe Touzet et Maya Dami, "Covid-19 : une application pratique de la force majeure", (6 Avril 2020).

https://www. parabellum.pro/Covid-19-une-application-pratique-de-la-forcemajeure_a856.html. (20/5/2020); Christine Sévère et Claire Picard, "COVID-19 Force majeure, fait du prince, imprévision et exception d'inexécution", Dentons (19 mars 2020). https://www.dentons.com/fr/insights/alerts/2020/march/19/covid-19-forcemajeure-contingency-and-default-exception .(20/5/2020).

${ }^{58}$ Nîmes, 6 nov. 2018, n 18/04133. 
ونفس الثىء بالنسبة لخطر الإصابة بالفيروس فإنه يجب أن يستجمع هذا الخطر شروط القوة القاهرة ومن بينها شرط عدم إمكان مقاومته، وقد ظهر ذلك في أحكام محكمة إستئناف كولمار كما وضحنا في الثرطين السابقين.

أما بالنسبة للندابير التي تتخذها الدولة لمواجهة الفيروس والتي قد ينشأ عنها حالة القوة القاهرة التي تمنع المدين من تتفيذ التزامه، مثلما رأينا في حكم محكمة استثناف باريس والتي اعثبرت القيود الحدودية التي تتطوي على حظر تصدير الماشية، بسبب وباء اللسان الأزرق، بمثابة القوة القاهرة؛ فإنه ينبغي التدقيق في نطاق تطبيق هذه التدابير بحيث إذا كان في الإمكان

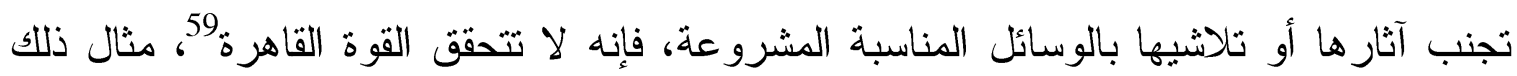
المورد الذب يلتزم بتوريد كمية معينة من البضائع كل فتزة زمنية محددة، وقد أُغلق مصنعه بقرار من الحكومة في إطار مكافحة الفيروس والسيطرة عليه، وكان ذلك بدون أن يثبت في جانبه أية خطأ استدعى هذا القرار، وكان لديه مصنع في الخار جيكنه تلبية الشحنات المطلوبة منه، فإنه لا يحق له الاحتجاج بالقوة القاهرة.

وفيما يتعلق بالعو اقب الاقتصادية الناتجة عن جائحة فيروس كورونا؛ فكما رأينا أن محكمة استئناف بورج اعتبرت أن العواقب الاقتصادية الناتجة عن وباء اللسان الأزرق الذي يصيب الماشية، قوة قاهرة لأنه كان لها أثز لايقاوم على نشاط المدين. و على خلاف ذلك ر أينا أن محكمة

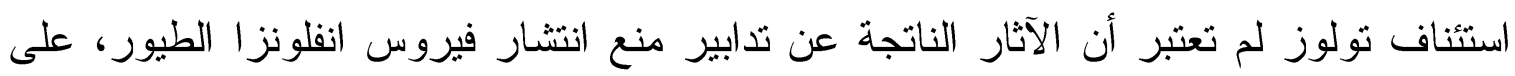
تشغيل المزرعة واستغلالها، لها طابع الحدث الذي لا يمكن التغلب عليه أو مقاومنه، وبالتالي لم

$$
59
$$

Allais et, al, "Impacts du Covid-19 en droit administratif, droits de l'homme, droit du travail, droit des contrats et droit penal", 18-20; David Sabatier, "La résiliation des contrats pour force majeure en raison du covid-19 / coronavirus", 1862 Avocats. https://www.1862-legal.com/blog-avocat-droit-immobilier/2020/3/15/doit-onsattendre-une-vague-de-rsiliation-des-contrats-pour-force-majeure-en-raison-ducovid-19-coronavirus- $\cdot(20 / 5 / 2020)$. 
تعتبر ها قوة قاهرة تبرر تخلف المدين عن سداد أجرة المزرعة. وبهذه المناسبة أود أن أثنير إلى أن العواقب الاقتصادية قد تتتج عن انتشار الفيروس ذاته حتى لو لم تتخذ الدولة إجراءات أو قرارات لمواجهة الفيروس من شأنها ترتيب آثار اقتصادية لا تقاوم، مثال ذلك إذا كان هناك مزارع قد التز ام بتوريد محصوله الزر اعي إلى آخر ، ثم بعد ذلك اجتاح فيروس دعين البلاد بشكل

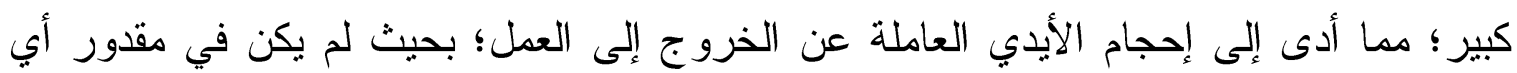
مز ارع وقتها العناية بمثل هذا المحصول بمفرده؛ فنتج عن ذلك فساده وتعذر إتمام عملية التوريد. وفي كل الأحوال ينبغي أن يتو افر في العو اقب الاقتصادية الناتجة عن جائحة كورونا(كوفيد-19)، الشروط الواجب نو افرها لكي تتحقق القوة القاهرة، ومنها ألا يكون في الإمكان مقاومنها

60 MEDEF, "L'impact duCovid-19 dans les relations contractuelles”, L'Association Nationale des Industries Alimentaires",1-2; Pierre Linais, "La force majeure : un remède contre le COVID-19 ?", Stephenson Harwood (avril 2020). https://www.shlegal.com/news/la-force-majeure-un-rem\%C3\%A8de-contre-le-covid19 .(20/5/2020); Elsa Haddad, "Le coronavirus et ses conséquences sur les contrats, cas de force majeure ou cause d'imprévision ?", village de lajustice (27 mars 2020). https://www.village-justice.com/articles/coronavirus-ses-consequences-sur-lescontrats-commerciaux-cas-force-majeure,34373.html .(20/5/2020). 


\section{Impossible رابعا: حادث من شأنه أن يجعل تتفيذ الالتز ام مستحيلا}

ينبغي بالإضافة إلى الثروط السابقة أن يجعل الحادث تتفيذ النزام المدين مستحيلا، فلا يكفى أن يؤدي إلى أن يكون تتفيذ الالتزام مرهقامَ؛ وهذا هو ما يميز نظرية القوة القاهرة عن الظروف الطارئة "La théorie de l'imprévision"، فيكفي لنطبيق الأخيرة أن يترتب على الحادث أن يصبح تتفيذ الالتز ام مرهقا لا مستحيلا كما في الأولى 62.

كما يجب أن تكون الاستحالة مطلقة وليست نسبية؛ أي أنه لا يكفي أن يستحيل تتفيذ الالتزام على المدين وحده بل على أي شخص في موقفه، ويسنوي أن تكون الاستحالة مادية أو معنوية . ${ }^{63}$ L'impossibilité matérielle ou morale

وقد قضت محكمة النقض المصرية فيما يتعلق بالثروط الواجب توفراها في الحادث لكي يصبح قوة قاهرة بأنه "... يجب أن يكون الحادث من شأنه أن يجعل ثتفيذ الالتزام مستحيلاً

61 راجع: السنهوري، الوسيط، 879؛ و نظرية العقد، 965؛ حسين عامر وعبدالرحيم عامر، العسئولية الدننية التقصبرية والعقدية، ط2( القاهرة: دار المعارف، 1979 )، 394؛ تناغو، مصادر الالتزام، 253.

وراجع أيضا: نقض مدني، الطعن رقم 27 لسنة 1 ق، جلسة 1932/1/14، مجموعة عمر ، المجلد الأول، ص

162 62 اجع: تناغو، مصادر الالتزام، 253؛ أحدد الصويعي شليبيك، " نظرية الظروف الطارئة: أركانها وشروطها"، الدجلة الأردنية في الدراسات الإسلامية 3، عدد 2 (2007): 185؛ خالد علي سليمان، "الفرق بين الفاءئ القوة القاهرة و الظروف الطارئة : دراسة مقارنة بين الفقه الإسلامى و القانون الوضعى"، الدجلة الواتلة الأردنية في

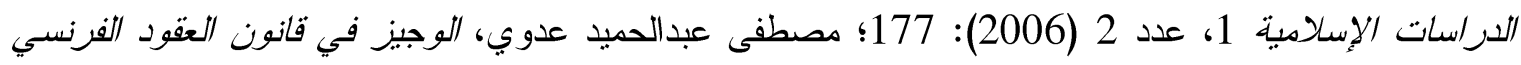

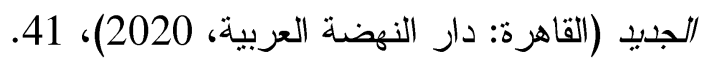

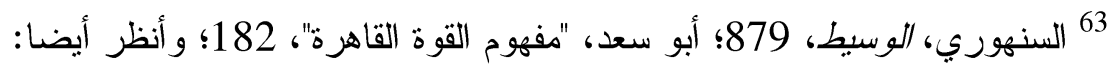
Jean VAN ZUYLEN, "La force majeure en matière contractuelle: un concept unifié? Réflexions à partir des droits belge, français et hollandaise", Revue Générale de Droit Civil Belge (RGDC), (Août 2013): 409,410.

https://dial.uclouvain.be/downloader/downloader.php?pid=boreal\%3A124936\&datastrea $\mathrm{m}=$ PDF_01\&disclaimer=201ef03c1361c49cc06e14481417850167e88ff716e7392eacaa $\underline{34 \mathrm{ca} 07 \mathrm{~d} 1 \mathrm{e} 5 \mathrm{f3}} \cdot(20 / 5 / 2020)$. 
استحالة مطلقة، فلا تكون استحالة بالنسبة إلى المدين وحده بل استحالة بالنسبة لأى شخص يكون

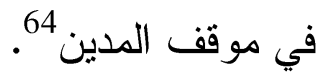
وجاء النص على هذا الثرط في المادة 1218 من القانون المدني الفرنسي والتي تتاولناها من قبل؛ فقد اشترطت أيضا في الحادث بالإضافة إلى الشروط السابقة أن يحول دون قبام المدين بتتفيذ التزامه 65. كما يتضح أيضا ذلك من أحكام محكمة النقض الفرنسية.66. وتطبيق ما سبق على جائحة فيروس كورونا المستجد يقتضي منا استعر اض السوابق القضائية التي تعرضت للأوبئة من زاوية استحالة تتفيذ الالتز ام نتيجة انتشار ها و الإدعاء بالقوة القاهرة من جانب المدين تبعا لذلك، لكي يكون من السهل علينا النظر أيضا إلى تلك الجائحة من نفس الزاوية. وفيما يتعلق بهذا الثأن قضت محكمة باريس الابتدائية في تاريخ 4 مايو 2004 برفض الدفع الذي قدمته إحدى وكالات السفر، بعدم قدرتها على تتفيذ التزامها، وهو القيام بالرحلة السياحية المخطط لها، بسبب القوة القاهرة المتمثلة في وجود فيروس سارس "SARS" في تايلاند، البلد المراد السفر إليه، وقد جاء في الحكم أن "المخاطر الصحية لم تكن كبيرة في تايلاند و لايمكن الاعتر اف بأن السفر إلى ذلك البلد كان مستحيلا بسبب فيروس سارس"67.6

$$
64 \text { نقض مدني، طعن رقم } 65 \text { راجع أيضا: } 7 \text { لسنة } 79 \text { قضائية، جلسة 2012/4/10، مكتب فني، س 63، ص589. }
$$

Moury, "Force majeure", 471; Jourdain, "Force majeure", 1477; Alain Sériaux, DROIT DES OBLIGATIONS, 2ème edition (Paris: Presses universitaires de France (PUF), 1998), 244; TOUAHRI, La responsabilité civile, 54.

${ }^{66}$ cass., Soc., 12 février $2003, N^{\circ}$ de pourvoi: 00-46660, Bulletin $2003 \vee N^{\circ} 50$ p. 45; Cass. civ., 4 août 1915, DP 1916, 1,p 22; cass, Com., 12 novembre 1969, JCP 1971 - II - 16791.

${ }^{67}$ TI Paris, 4 mai 2004, $\mathrm{n}^{\circ} 11-03-000869$;

وراجع أيضا:

Catherine Leclercq, “PEUT-ON S'EXONÉRER DU PAIEMENT DE SON LOYER COMMERCIAL DANS LE CONTEXTE DU COVID-19 ?", village justice (4/4/2020). 
وقضت أيضا نفس المحكمة في تاريخ 25 سبتمبر عام 1998 بأن التوقف في بلا مجاور لمنطقة تفشى فيها وباء الطاعون épidémie de peste لا يمكن اعنباره قوة قاهرة تبرر إلغاء المسافرين حجز رحلاتهم المخطط لها؛ حيث لم يكن انتشار الوباء في المنطقة المجاورة لمحطة التوقف، جسيما ولم توجه أي تعليمات لشركات الطيران أو وكالات السفر لتفادي تلك المنطقة.68. و هذا يعني أيضا أن تنفيذ الالتزام لم يكن مستحيلا بسبب الوباء المذكور.

كما قضت محكمة استئناف باريس في تاريخ 17 مارس 2016، فيما يتعلق بشركة استندت في تخلفها عن سداد اشتراكات الضمان الاجتماعي، إلى القوة القاهرة المتمنتة في انتشار وباء إيبو لا Ebola ؛ بأن الطبيعة المؤكدة للوباء الذي ضرب غرب إفريقيا إعتبار ا من ديسمبر 2013، لم تكن كافية، حتى لو أُعتبر الوباء قوة قاهرة، لإثبات أن ذلك تسبب في انخفاض أو عدم وجود لهود النقد؛ فلم تقدم الثركة دليلا على أن عدم دفع اشتراكات الضمان الاجتماعي كان بسبب القوة القاهرة.69.

وفيما يتعلق بجائحة فيروس كورونا المستجد فإنه ينبني على المدين الذي يستتد إلى القوة القاهرة في هذا السياق، تقديم الأدلة للمحكمة التي تثبت أن عدم تتفيذه لالتزامه كان نتيجة تلك الجائحة، فإذا كان ما ادعى به من قوة قاهرة يتمثل في الإصابة بالفيروس فإن عليه إثبات أن الإصابة هي السبب في جعل تتفيذ الالتزام مستحيلا؛ فإذا كان على سبيل المثال تتفيذ الالتزام لا يتطلب وجوده؛ بحيث كان من الممكن القيام به عن طريق أحد من ذويه أو العاملين لديه أو كان

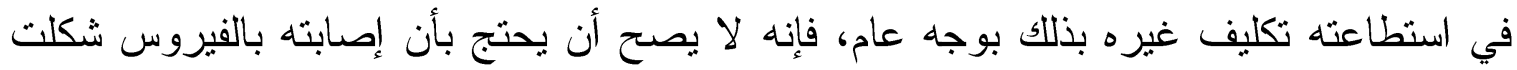
قوة قاهرة منعته من التنفيذ، ونفس الثىء لو كانت الإصابة بالفيروس التي يحتج بها كقوة قاهرة،

$==$ https://www.village-justice.com/articles/peut-exonerer-paiement-son-loyercommercial-dans-contexte-covid,34482.htm\#nh2-1 .(15/4/2020).

68 Paris, 25e, section B, 25 sept. 1998, n Juris-Data 1998-024244.

${ }^{69}$ CA Paris, 17 mars 2016, $\mathrm{n}^{\circ}$ 15/04263.

https://www.doctrine.fr/d/CA/Paris/2016/RD450B9F0892CE28A7EF5 .(18/5/2020). 
تتمثل في إصابة عماله، فلايصح إذا لم يتأثر العمل بذلك بحيث كان في الإمكان تتفيذ الالتزام، أن يستتد إلى ذلك لتبرير عدم تتفيذ الالتزام. وبالتالي الإصابة التي يعول عليها هنا هي التي من شأنها أن تجعل تتفيذ الالتزام مستحيلا، ويجب على المدين تقديم الدليل على ذلك. و أما إذا ادعى بأن القوة القاهرة تتمثل في مخاطر العدوى؛ أي أن خشيته من الإصابة بالفيروس منعته من تتفيذ الالنزام، فإنه ينبغي في هذه الحالة أن يقدم الدليل على أن الفيروس كان من الجسامة بحيث يخشى على حياة الإنسان من التفاعل الاجتماعي الذي يقتيه تتفيذ الالتزام. وقريب من ذلك ما استخلصته محكمة استئناف كولمار بشأن مخاطر العدوى بفيروس كورونا المستجد، في أحكامها التي ذكرناها من قبل، فقد استقر في عقيدتها أنه ليس هنالك ما يضمن عدم انتقال الفيروس للغير عند إحضار المحتجزين إلى جلسات المحكمة. و إذا كانت تلك الأحكام تتعلق بالمسائل الإجر ائية وليس تتفيذ العقود؛ لكننا نستطيع من خلالها أن نتصور معنى الاستحالة التي تتتج عن مخاطر العدوى بفيروس كورونا، عندما يزعم المدين أن هذه المخاطر تمثل قوة قاهرة من شأنها أن تجعل تتفيذ التز امه مستحيلا. وكان هناك تطبيق لذلك على فيروسات سابقة في إطار تتفيذ العقود المدنية؛ فلم تقتع محكمة باريس الابتدائية في مناسبتين وضحناهما أعلاه بأن المخاطر الصحية للوباء، سواء سارس أو الطاعون، لم تكن كافية للاعتز اف بأنها جعلت تتفيذ الالتز ام مستحيلا.

ونفس الأمر إذا كانت القوة القاهرة التي يحتج بها المدين تتمثل في التدابير التي اتخذتها الدولة لمواجهة الفيروس؛ فينبغي أيضا أن يقدم الدليل على أن ذلك تسبب في جعل تتفيذ التزامه مستحيلا، ويقتي النظر في هذه المسألة من قبل المحكمة فحص شروط تطبيق تلك التدابير؛ فإذا لم يكن من شأنها أن تجعل تتفيذ الالتزام مستحيلا كما يدعي المدين، فإن الأخير لا يكون محقا في دعواه أو ادعائه، مثال ذلك إذا كان قرار حظر التجوال الذي فرضته الدولة يستثني من نطاق تطبيقه بعض الأنشطة، وكان نشاطه من الأنشطة المستثاه؛ فإنه لا يجوز له الاحتجاج بأن ذلك القز ار كان سبيا في إعاقته عن تتفيذ التزامه، لما انطوى عليه من تقييد للحركة.

وينطبق ذلك على العو اقب الاقتصادية الناشئة عن الجائحة والتي قد يحتج بها الددين كقوة قاهرة منعته من تتفيذ التزامه؛ بحيث ينبغي أيضا أن يقدم الدليل على أن تلك العو اقب كانت السبب 
في وراء استحالة التتفيذ. وقد رأينا أن محكمة استئناف باريس رفضت التسليم بذلك في قضية ادعى فيها المدين بأنه لم يكن قادر ا على سداد اشتركات الضمان الاجتماعي بسبب فيروس إيبو لا. والاستحالة الناشئة عن جائحة فيروس كورونا المستجد قد تكون استحالة جزئية، وفي هذه الحالة لا ينقضي التزام المدين كلية إذا كان في الإمكان القيام بالجزء الآخر ويبقى أيضا ما يقابله من التزامات تقع على عاتق الدائن 70، والأمثلة على ذلك عديدة ومنها إذا كان التزام المدين بتمثل في توريد أصناف معينة من المواد الغذائية خارج البلاد، وكانت الدولة على أثر انتشار الفيروس حظرت تصدير البقوليات، فإنه يظل مع ذلك ملتزما بتوريد الأصناف الأخرى غير البقوليات. ومع ذلك إذا كان الالتز ام غير قابل للتجزئة indivisible أو أن الجزء المتنقى منه لم يعد مفيدا للائن أو أن التنفيذ الجزئي يتتاقض مع إرادة المتعاقدين، فإن الالتزام ينقضي في هذه الحالات كلية، والأمر متروك لقاضي الموضو ع 71.

${ }^{70}$ MEDEF, "L'impact du Covid-19 dans les relations contractuelles", 2; Valérie Ledoux, "Coronavirus et (in)exécution du contrat d'affaires", Racine Avocats(2 Avril 2020): 2. https://www.racine.eu/wp-content/uploads/2020/04/coronavirus-et-inexecution-ducontrat-daffaires-02042020-2.pdf .(20/5/2020);

Vincent FAUCHOUX, "COVID-19 | Coronavirus et force majeure : quels impacts sur vos contrats ?", Deprez Guignot Associates, "DDG', (2-3-2020).

https://ddg.fr/actualite/coronavirus-et-force-majeure/ $\cdot(20 / 5 / 2020)$.

71 راجع: عامر و عامر ، الدسئولية الدننية، 399؛ وأنظر أيضا:

Uggc Avocats, "LE COVID-19 CONSTITUE-T-IL UN CAS DE FORCE MAJEURE ? QUELS EN SONT LES EFFETS SUR LES CONTRATS EN COURS ?", UggC $(16 / 04 / 2020)$.

https://www.uggc.com/le-covid-19-constitue-t-il-un-cas-de-force-majeure-quelsen-sont-les-effets-sur-les-contrats-en-cours/.(20/5/2020).

و أنظر أيضا حكم محكمة النقض الفرنسية التالي: Cass Civ, 1er , 13 janvier 1987, Nº de pourvoi: 85-12676, Bulletin 1987 I No 11 p. 8. 
وقد تكون الاستحالة الناتجة عن جائحة فيروس كورونا المستجد مؤقتة Temporaire، وفي هذه الحالة يعلق أداء الالتزام حتى يزول العائق الذي منع المدين من التتفيذ7، مثال ذلك إذا حظرت الدولة تصدير المواد اللازمة للوقاية من الفيروس، كالمطهرات والأقنعة وغيرها، وكان محل التزام المدين توريد هذه المواد خارج البلاد، فهنا يبقى التزام المدين قائم حتى إلغاء قرار الحظر، ومع ذلك فإن الالتز ام ينقضي إذا كان تعليقه يجرده من أية منفعة تعود على الدائن أو كانت إرداة المتعاقدين قد اتجهت إلى أن أداء الالتز ام يتعين أن يكون فوريا في كل الأحو ال أو في موعد محدد يعول الدائن عليه لتحقيق مصلحة معينة أو أن الههف الذي يسعى إليه المتعاقدين يتناقض مع تعليق تتفيذ العقد. و إذا جرى تعليق أداء الالتزام حتى أصبح تتفيذه بلا جدوى، فإن الالتز ام ينقي أيضا، وكل ذلك متروك لقاضي الموضوع يحدده بحسب ظروف كل حالة.73.

\footnotetext{
${ }^{72}$ Frédéric Danos, "La crise du coronavirus et l'exécution des engagements contractuels", Editions legislatives (30.03.2020).

https://www.editions-legislatives.fr/actualite/la-crise-du-coronavirus-et-
} I\%E2\%80\%99execution-des-engagements-contractuels .(22/5/2020); JOUCLARD Alexandra, "Le coronavirus n'excuse pas tout", linkedin (7/4/2020).

https://www.linkedin.com/pulse/le-coronavirus-nexcuse-pas-tout-jouclard-alexandra/ .(22/5/2020); Philippe Axelrouode, "L'épidémie de Covid-19 peut-elle justifier la rupture d'un contrat de travail sur le fondement de la force majeure?", Pragma (30/04/2020). https://pragma.international/article/lepidemie-de-covid-19-peut-ellejustifier-la-rupture-dun-contrat-de-travail-sur-le-fondement .(22/5/2020);

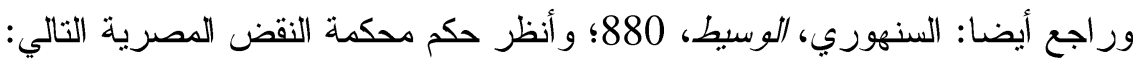

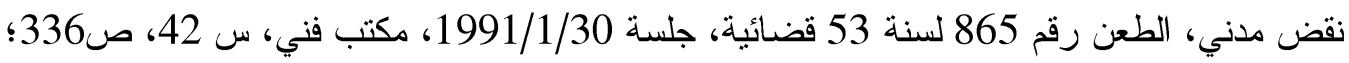
وكنلك حكم محكمة النقض الفرنسية التالي:

Cass., 1 ère Civ., 24 février 1981, $\mathrm{N}^{\circ}$ de pourvoi: 79-12710, Bulletin N. 65. https://www.legifrance.gouv.fr/affichJuriJudi.do?idTexte=JURITEXT000007007126 .$(20 / 5 / 2020)$.

$$
\text { 73 راجع: عامر و عامر ، المسئولية الدننية، 399، 400. }
$$


و إذا ثبت أن جائحة فيروس كورونا المستجد كانت السبب الوحيد في الاستحالة النهائية لتنفيذ الالتزام ووقوع الضرر بالدائن، فإن الالتز ام ينقضي وفقا لنص المادة 373 من القانون المدني المصري، وتتقضي الالتزامات المقابلة وينفسخ العقد من تلقاء نفسه وفقا لنص المادة 159 من

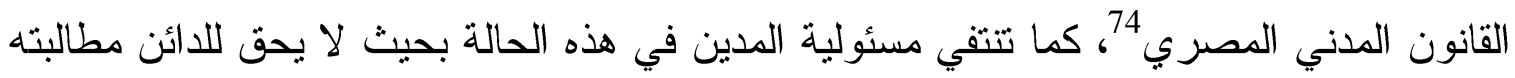
بأية تعويض عن ذلك، وذلك لانتفاء علاقة السببية عن طريق القوة القاهرة، تطبيقا لنص المادة 215 من القانون المدني المصري 75، وقد أثنرنا إلى المواد الثناث أثناء شرحنا للشرط الأول.

وقد نصت المادة 2/1218 من القانون المدني الفرنسي في هذا الثأن على أنه" إذا كان المانع مؤقتا يتم تعليق تتفيذ الالتزام، مالم يبرر التأخير الناتج عنه إنهاء العقد. إذا كان المانع نهائيا يتم إنهاء العقد تلقائيا ويتحرر الأطر اف من التزاماتهم بموجب الثروط المنصوص عليها في المادنين .$^{76 " 1-1351 ، 1351}$

le ومع ذلك ينبغي على المدين أن يتصرف وفقا لما يقتضيه مبدأ حسن النية في تتفيذ العقود principe de la bonne foi مدني فرنسي 77؛ بحيث يتعين عليه إخطار الدائن بأمر استحالة تتفيذ الالتزام لكي يتمكن من اتخاذ التدابير و استخدام الوسائل التي تحد من الخسائر التي قد تلحق به جراء ذلك، ويكون ذلك في

$$
\begin{aligned}
& \text { 74 راجع في هذا الثأن: السنهوري، الوسيط، 722-727. } \\
& \text { 75 راجع: الدرجع السابق، } 880 .
\end{aligned}
$$

76 Article 1218-2: Si l'empêchement est temporaire, l'exécution de l'obligation est suspendue à moins que le retard qui en résulterait ne justifie la résolution du contrat. $\mathrm{Si}$ l'empêchement est définitif, le contrat est résolu de plein droit et les parties sont libérées de leurs obligations dans les conditions prévues aux articles 1351 et 1351-1. 77 تنص المادة 1/148 مدني مصري على أنه: يجب تنفيذ العقد طبقا لما اثنتل عليه وبطريقة تتفق مع ما يوجبه حسن النية؛ وتتص المادة 1104 مدني فرنسي على أنه: يجب التفاوض على العقود وتكوينها وتنفيذها بحسن نية. هذا الحكم

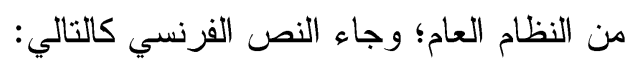
Les contrats doivent être négociés, formés et exécutés de bonne foi. Cette disposition est d'ordre public. 
أقرب وقت يتمكن فيه المدين من القيام بذلك. كما ينبغي عليه أن يقوم بالعناية المتوقعة من الشخص المعتاد لمنع الأضر ار التي قد تصيب الدائن بسبب القوة القاهرة أو التخفيف منها، ومن ناحية أخرى ينبغي على الدائن أن يقوم بكل ما تفرضه مقتضيات حسن النية و التعاون في تتفيذ العقد أيضا؛ ويترتب على ذلك أن يقوم بكل ما يساهم في تخفيف الأعباء عن المدين وأن يمتتع عن أي سلوك من شأنه زيادة تلك الأعباء 78.

و الجدير بالذكر أخير أنه يجوز الاتفاق بين المتعاقدين على تعديل أثز القوة القاهرة؛ بمعنى أنه يصح أن يتفق الطرفان على أن يتحمل المدين تبعة القوة القاهرة؛79 وفي هذا الثأن تتص المادة 1/217 على أنه "يجوز الاتفاق على أن يتحمل المدين تبعة الحادث المفاجئ والقوة القاهرة". ويسأل المدين عن تتفيذ الالتزام وفقا للمادة 1351 من القانون المدني الفرنسي، على الرغم من تحقق القوة القاهرة، في حالتين إذا كان هناك اتفاق على ذلك أو إذا كان قد أخطر بالتتفيذ ووقعت القوة القاهرة قبل قبامه بذلكه8، ومع ذلك فإنه وفقا للمادة 1- 1351 إذا كانت استحالة التتفيذ

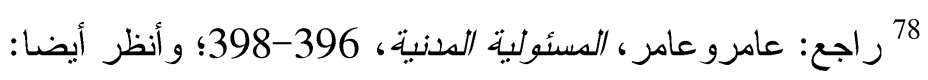

FAUCHOUX, "COVID-19 | Coronavirus et force majeure",; Celine Taieb, "Contrat commerciaux et Coronavirus", Alaris Avocats (21-3-2020).

https://www.alaris-law.com/fr/contrat-commerciaux-et-coronavirus/ .(22/5/2020); Nicolas Rémy-Néris, "L'exécution des contrats commerciaux à l'épreuve du Covid-19", Grant Thornton (1-4-2020). https://www.grantthornton.fr/fr/insights/articles-et-publications/2020/lexecution-descontrats-commerciaux-a-lepreuve-du-covid-19/.(22/5/2020).

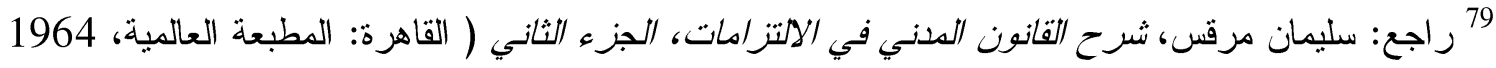

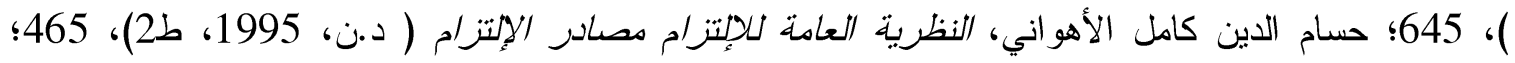

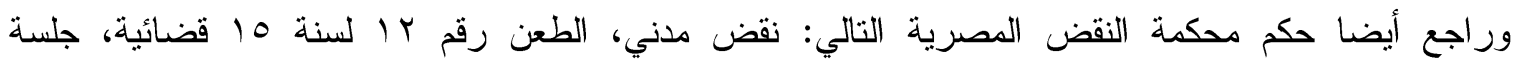
$.1945 / 10 / 29$ https://www.cc.gov.eg/judgment_single?id=111331605\&\&ja=126664 $\cdot(22 / 5 / 2020)$. 80 أنظر : محمد عرفان الخطيب، "المبادئ المؤطرة لنظرية العقد في التنشريع المدني الفرنسي الجديد: دراسة النة

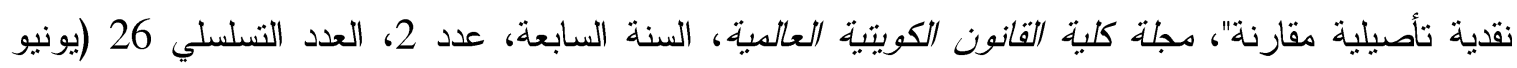

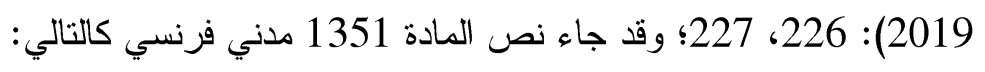


بسبب هلاكك الثيء المستحق فإنه تتتفي مسئولية المدين رغم إخطاره إذا ثبت أن ذلك كان سيحدث حتى لو ثم تتفيذ الالتزام 81. وقد يتخذ الاتفاق على تعديل أثر القوة القاهرة صورة الاتفاق على أن يتحمل المدين القوة القاهرة بوجه عام ولا تتتفي مسئوليته إذا تحققت، أو الاتفاق على أن هناك أحداث معينة تعد قوة قاهرة وتتنفي مسئولية المدين إذا وقع حادث منها دون غبرها أو الاتفاق على أن مسئولية المدين تبقى قائمة إذا وقعت حو ادث معينة دون غيرهاتهات

$==L$ 'impossibilité d'exécuter la prestation libère le débiteur à due concurrence lorsqu'elle procède d'un cas de force majeure et qu'elle est définitive, à moins qu'il n'ait convenu de s'en charger ou qu'il ait été préalablement mis en demeure.

${ }^{81}$ Article 1351-1: Lorsque l'impossibilité d'exécuter résulte de la perte de la chose due, le débiteur mis en demeure est néanmoins libéré s'il prouve que la perte se serait pareillement produite si l'obligation avait été exécutée. II est cependant tenu de céder à son créancier les droits et actions attachés à la chose.

${ }^{82}$ Christine Sévère et Claire Picard, "COVID-19 Force majeure, fait du prince, imprévision et exception d'inexécution", dentons (19-3-2020).

https://www.dentons.com/fr/insights/alerts/2020/march/19/covid-19-force-majeurecontingency-and-default-exception .(22/5/2020). 


\section{خاتمة}

بعد أن انتهينا من دراستتا لموضوع مدى انطباق نظرية القوة القاهرة على جائحة فيروس كورونا (SARS-CoV-2)، وذلك من خلال تحديد المقصود بالقوة القاهرة في البداية ثم تطبيق شروط تحققها على تلك الجائحة بعد ذلك، نستطيع أن نبين هنا أهم النتائج التي توصلنا إليها من البحث و أهم التوصيات التي تتعلق بذلك وكذلك الدراسات المستقلية التي يمكننا اقتراحها فيما يخص هذا الثأن، ونفصل ذلك فيما يلي:

\section{أولا: النتائج العلمية}

1- اتضح لنا من خلال التعريفات التي بيناها للقوة القاهرة أن هناك أربعة شروط يجب تو افرها في الحادث لكي يوصف بأنه قوة قاهرة، وهي: وجوب أن يكون حادثا خارجيا، ليس في الإمكان توقعه، كما لا يمكن مقاومته ويجعل تتفيذ الالتز ام مستحيلا. 2-تبين لنا من خلال تطبيق الشروط المذكورة أعلاه على جائحة فيروس كورونا المستجد أن القوة القاهرة فيما ينعلق بذلك يمكن أن تتمنل في الإصابة بالفيروس أو خطر العدوى به إذا وصل الفيروس حدا من الجسامة يخشى معها على حياة الإنسان من التفاعل الاجنماعي الخارجي، كما يمكن أن تتمنل أيضا في التدابير الحكومية التي تتخذها الدولة لمواجهة الفيروس أو العو اقب الاقتصادية الناشئة عنه، وفي كل الأحو ال يجب أن ينو افر في الصور المذكورة شروط تحقق القوة القاهرة الني عرضناها أعلاه؛ بحيث نستطيع القول أن جائحة فيروس كورونا المستجد ليست بذاتها قوة قاهرة بشكل تلقائي في جميع الحالات بل ينبغي النظر في آثار ها ومدى تحقق تلك الثروط بشأنها بحسب كل حالة على حده؛ و الأمر منروك لمحكمة الموضوع. 3-تكرار الفيروس لا يعني افتر اض توقع حدوثه ومن ثم عدم تحقق القوة القاهرة فيما يخص الاحتجاج بالأثار الناتجة عنه؛ بل إذا تكرر ظهور فيروس؛ بحيث لم يكن في الإمكان توقع نطاقه أو شدته أو حدته أو كان نادر ا بحيث لا يوجد سبب خاص لتوقع حدوثه وقت 
التعاقد، فإن ذلك لا يمنع تحقق القوة القاهرة إذا تو افرت شروطها الأخرى، ويظهر ذلك بجلاء في حالة الفيروس المستوطن Endémie. 4- الإعلان عن الفيروس من قبل منظمة الصحة العالمية أو الدولة لا يصلح ضابطا لتقدير شرط عدم توقع الفيروس من جانب المدين و إنما يجب الرجوع إلى معيار الثخص المعتاد مع مر اعاة الظروف المحيطة. 5- الحفاظ على نسبية القوة القاهرة من حيث ثقدير شرط عدم نوقع الحدث وكذلك شرط عدم القدرة على مقاومته، بالرجوع إلى معيار الشخص المعتاد في نفس الظروف؛ يضمن تحقها وفقا للتوقعات والقدرات المعقولة للمتعاقدين، بما يرفع عن المدين المعاناة وقت الأزمات التي تحدث بعد إير ام العقد وتجعل تتفيذ الالتز ام مستحيلا. 6- إذا كانت القوة القاهرة المتمثلة في أحد آثار جائحة فيروس كورونا المستجد، هي السبب الوحيد في الاستحالة النهائية للالتزام، تزثب عليها انقضاء الالتزام و انتفاء مسئولية المدين؛ بينما إذا ترثب على القوة القاهرة مجرد الاستحالة المؤقتة لتتفيذ الالتزام، فإن الأخير لا ينقضي و إنما يعلق تتفيذه حتى زوال العائق المؤقت الذي يحول دون ذلك مع مر اعاة القواعد العامة في هذا الثأن وفقا لما وضحناه في البحث، كما أنه قد تكون الاستحالة الناتجة عن القوة القاهرة استحالة جزئية وليست كلية وهنا لا ينقضي الثزام المدين كلية و إنما يقتصر ذلك على الجزء الذي استحال تتفيذه فقط وكذلك الجزء الدقابل له من التزام الدائن، مع مر اعاة القو اعد العامة في هذا الثأن أيضـا.

\section{ثانيا: التوصيات}

1-نوصي المشرع بصياغة أحكام القوة القاهرة على غرار ما قام به المشرع الفرنسي في

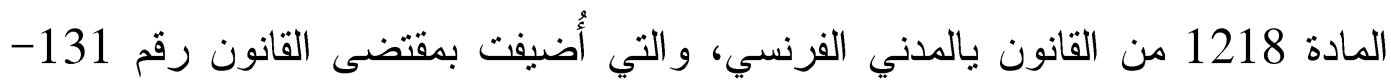
.2016

2-نوصي الحكومة باتخاذ القرارات اللازمة للحفاظ على حركة التجارة الداخلية والدولية وقت الأزمة الصحية بما يضمن الوفاء بالالتزامات التعاقدية قدر المستطاع. 
3-نوصي المحاكم القضائية باتباع النهج النسبي عند تقدير تو افر شرطي عدم القدرة على توقع الحدث و عدم إمكان مقاومته، لتحديد مدى تحقق القوة القاهرة بوجه عام، وفيما يتعلق بجائحة فيروس كورونا المستجد على وجه الخصوص؛ وذلك بالرجوع إلى دعيار الثخص المعتاد مع مر اعاة الظروف المحيطة.

\section{ثالثا: الدر اسات المستقبلية}

1- الالتزام بمبدأ حسن النية أثناء تتفيذ العقد له دور كبير في الحفاظ عليه من تعرضد للإنفساخ بسبب القوة القاهرة، كما أن له دور أيضا في التخفيف من آثار القوة القاهرة عندما لا يكون هناك مفر من تحققها؛ ويقتضي هذا الأمر دراسة المبدأ المذكور لتوضيح ما يجب أن يقوم به الطرفان فيما يتعلق بهذا الثأن. 2- يمكن أن تسبب الآثار الناجمة عن جائحة فيروس كورونا المستجد، والتي تطر أ أثناء تتفيذ العقد أن يصبح تتفيذ الالتز ام مرهقا للمدين وليس مستحيلا عليه؛ ويأت هنا دور نظرية الظروف الطارئة كوسيلة لرفع المعاناة عن المدين و إعادة التوازن العقدي، ونقتر ح أيضـا دراسة الأمر من هذه الزاوية.

3-تثير أيضا جائحة فيروس كورونا المستجد موضوع المسئولية المدنية عن الإصابة بالفيروس ونقل العدوى، ويصلح ذلك أيضا موضوع در اسة مستقلة في المستقبل. 4-نقترح أيضا تتاول الضمان الاجتماعي وحماية الفئات المتضررة من آثار انتثار الفيروس، بالبحث والدراسة لما له من أهمية في إبراز الإطار القانوني للمسئولية الاجتماعية عن ذلك.

5- تحديد انعكاسات جائحة فيروس كورونا المستجد على عقد العمل يحتاج إلى دراسة مستقلة لبيان التزامات صاحب العمل وحقوق العامل أثناء تلك الجائحة. 


\section{قائمة المر اجع}

\section{أولا: المر اجع باللغة العربية}

- - أبو سعد، محمد شتا. "مفهوم القوة القاهرة"، مجلة مصر الدعاصرة، الجمعية الدصرية للاقتصاد السياسي والإحصاء والنتريع 78، عدد 1983،393، 1983). 195.

- أبو السعود، رمضان. النظربة العامة للالتز/م، مصادر الالتز/م. الاسكندرية: دار المطبوعات الجامعية، 2002. - - الأهو اني، حسام الدين كامل. النظرية العامة للإلتزام مصادر الإلتز/م. د.ن، 1995، ط2. - الأيوبي، محمد." المركز القانوني للمدين في واقعة فيروس "كورونا كوفيد 19". سلسلة إحباء علوم القانون، المغرب (مايو 2020). 287-296.

- - البكري، محمد عزمي ، دعوى التعويض. القاهرة: دار محمود للنشر و التوزيع، 2007. - - الخضر اوي، محمد." الآثار القانونية لفيروس كورونا المستجد على الالتز امات التعاقدية". سلسلة إحياء علوم القانون، المغرب (مايو 2020): 268-272.

- - الخطيب، محمد عرفان ، "المبادئ المؤطرة لنظرية العقد في التشريع المدني الفرنسي الجديد: در اسة نقدية تأصيلية مقارنة". مجلة كلية القانون الكويتية العالمية، السنة السابعة، عدد 2، العدد النسلسلي 26 (يونيو 2019): 183-

- - السنهوري، عبدالرزاق أحمد. الوسيط في شرح القانون المدني، الجزء الأول، نظرية الالتزام بوجه عام، مصادر الالتز/م. بيروت، لبنان: دار إحياء التزاث العربي، 1970.

- - -- - نظرية العقد، الجزء الثاني. بيروت، لبنان: منشور ات الحلبي الحقوقية،ط 2، 1998.

- - الدناصوري، عز الدين و عبدالحميد الثواربي. المسئولية الددنية في ضوء الفقه و القضاء. الاسكندرية: منشأة

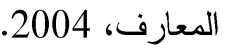

- الكعبي، محمد عبد الصاحب. المسؤولية المدنية عن أضرار الكوارث الطبيعية: (در اسة مقارنة). الإسكندرية: دار التعليم الجامعي، 2019. - بحار، عبدالرحيم." أثر وباء كورونا المستجد كوفيد 19 على الالتز امات التجارية". سلسلة إحياء علوم القانون، المغرب (مايو 2020). 384-390 
- - تناغو، سمير عبدالسيد. مصادر الالتز/م. الاسكندرية: مكتبة الوفاء القانونية، 2009.

- حمة، بن خدة. "قز اءة في أهم مستجدات الإصلاح الجذري للقانون المدني الفرنسي لسنة 2016 ومدى تأثير ها على القانون المدني الجزائري في ثوبه الحالي". مجلة الأستاذ الباحث للدراسات القانونية والسياسية، عدد 11 (سبتمبر 2018). 417-447.

- رضوان، أمينة و المصطفى الفوركي. " تأثير فيروس كورونا على الالتز امات التعاقدية"، سلسلة إحياء علوم القانون، المغرب (مايو 2020): 273-286.

- - سعد، نبيل إبر اهيم. النظرية العامة للالتزام، مصادر الالتز/م. الاسكندرية: دار الجامعة الجديدة، 2004. - - سلطان، أنور • مصادر الالتز/م في القانون الدني. دراسة مقارنة بالفقه الإسلامي. عمّان، الأردن: دار الثقافة للنشر و التوزيع، 2012.

- - سليم، محمد محيي الدين. نظرية الظروف الطارئة بين القانون المنسي والفقه الإسلامي. الاسكندرية: دار المطبو عات الجامعية، 2007.

- سليمان، خالد علي. "الفرق بين القوة القاهرة و الظروف الطارئة : دراسة مقارنة بين الفقه الإسلامى و القانون الوضعى". المجلة الأردنية في الدراسات الإسلاعبة 1، عدد 2 (2006): 169-187.

- شلييك، أحمد الصويعي. " نظرية الظروف الطارئة: أركانها وشروطها". المجلة الأردنية في الدراسات الإسلامية 3، عدد 2 (2007): 169-198.

- - شنب، محمد لبيب. المسئولية عن الأشياء دراسة في الفانون المدني المصري مقارنا بالقانون الفرنسي. القاهرة: مكتبة النهضة المصرية، 1957.

- عامر ، حسين و عبدالرحيم عامر • المسئولية الدنية الثقصبرية و العقدية، ط2. القاهرة: دار المعارف، 1979. - عدوي، مصطفى عبدالحميد. الوجيز في قانون العقود الفرنسي الجديد. القاهرة: دار النهضة العربية، 2020. - غنام، شريف محمد. أثر تغبير الظروف في عقود النجارة الدولية. دبي، الإمار ات العربية المتحدة: أكاديمية شرطة دبي، 2010.

- مرسي، محمد كامل. شرح القانون المدني الجديد، الجزء الثاني، الالتزامات. القاهرة: المطبعة العالمية، 1955. - - مرقس، سليمان. شرح القانون الدني في الالتزامات، الجزء الثاني. القاهرة: المطبعة العالمية، 1964. 


$$
\begin{aligned}
& \text { - - مريم، يــلى. إلتززام العون الاقتصادي بالتسليم الدطابق. رسالة دكتور اه، كلية الحقوق و العلوم السياسية، جامعة } \\
& \text { أبو بكر بلقايد، تلمسان، الجزائر، 2017/2016. } \\
& \text { - يف، مروان. " مآل تتفيذ الالتز امات النعاقدية في ظل فيروس كورونا-كوفيد 19-بين إعتباره قوة قاهرة أم } \\
& \text { ظرف طارىء". سلسلة إحياء علوم القانون، المغرب (مايو 2020). 314-335. } \\
& \text { ثانيا: المر اجع باللغة الفرنسية }
\end{aligned}
$$

- $\quad$ Alexandra, JOUCLARD. “Le coronavirus n'excuse pas tout”. linkedin (7/4/2020). https://www.linkedin.com/pulse/le-coronavirus-nexcuse-pas-tout-jouclard-alexandra/ .(22/5/2020).

- Avocats, Uggc, "LE COVID-19 CONSTITUE-T-IL UN CAS DE FORCE MAJEURE ? QUELS EN SONT LES EFFETS SUR LES CONTRATS EN COURS ?". Uggc (16/04/2020).

https://www.uggc.com/le-covid-19-constitue-t-il-un-cas-de-force-majeure-quels-ensont-les-effets-sur-les-contrats-en-cours/.(20/5/2020).

- $\quad$ Axelrouode,Philippe. "L'épidémie de Covid-19 peut-elle justifier la rupture d'un contrat de travail sur le fondement de la force majeure?". Pragma (30/04/2020).https://pragma.international/article/lepidemie-de-covid-19-peut-ellejustifier-la-rupture-dun-contrat-de-travail-sur-le-fondement .(22/5/2020);

- Azaïs Xavier. "CORONAVIRUS (COVID-19) : FAUT-IL PRÉFÉRER L'IMPRÉVISION À LA FORCE MAJEURE ?". village de la justice (19 MARS 2020). https://www.villagejustice.com/articles/coronavirus-covid-faut-preferer-imprevision-forcemajeure,34184.html. (30/3/2020).

- Balensi, Benjamin et Gisèle-Aimée Milandou. "Coronavirus : quel usage de la force majeure dans les contrats commerciaux ?". taj, (24 mars 2020). https://tajstrategie.fr/coronavirus-usage-de-force-majeure-contrats-commerciaux. (29/3/2020).

- Bensussan, Philippe. "Le sort des loyers en matière de bail commercial à l'épreuve du COVID-19", LE MONDE DU DROIT (2 AVRIL 2020). https://www.lemondedudroit.fr/decryptages/69198-sort-loyers-bail-commercialcovid19-coronavirus.html . (20/5/2020).

- Chabas, François. "La force majeure". Dalloz, n 13. (septembre 2002).

- Clément Allais, Amelle Djedi, Soukaina El-Mekkaoui, Christelle Meda et Ekaterina Oleinikova, stagiaires et élèves avocats (EFB École de Formation du Barreau) de Navacelle. "Impacts du Covid-19 en droit administratif, droits de l'homme, droit du travail, droit des contrats et droit penal". NAVACELLE (2020): 129.http://navacellelaw.com/wpcontent/uploads/NavacelleSynthesedesconsequencesdu Covid-19.pdf. (28/3/2020).

- Danos, Frédéric. "La crise du coronavirus et l'exécution des engagements contractuels". Editions legislatives (30.03.2020).https://www.editions-legislatives.fr/actualite/la-crisedu-coronavirus-et-I\%E2\%80\%99execution-des-engagements-contractuels .(22/5/2020). 
- $\quad$ Daouda, ZAN. "L'IMPACT DU CORONAVIRUS(COVID-19) SUR LE CONTRAT DE TRAVAIL". Revue Juridique du Faso (31/3/2020). https://revuejuris.net/2020/03/31/limpact-ducoronaviruscovid-19-sur-le-contrat-de-travail/ .(15/4/2020).

- de Taddéo, Isabelle. "LA NOTION DE FORCE MAJEURE". (Janvier 2005): 13.http://jl.droit.free.fr/docs/La\%20notion\%20de\%20force\%20majeure.pdf .(1/4/2020).

- $\quad$ DIAZ , Me Clément. "Le Covid19 constitue-t-il un cas de force majeure pouvant justifier I'inexécution d'une obligation contractuelle ?".Avocat.fr, Blog des avocats, Blog de Me Clément DIAZ (27/5/2020). https://consultation.avocat.fr/blog/clement-diaz/article35228-le-covid19-constitue-t-il-un-cas-de-force-majeure-pouvant-justifier-I-inexecutiond-une-obligation-contractuelle.html .(29/5/2020).

- DOMAT, Didier. Neal LACHMANY et Alexandre DANION. "Les contrats de sponsoring des clubs sportifs à l'épreuve de l'épidémie de covid-19", doctrine actu (21/4/2020).https://www.doctrinactu.fr/post/les-contrats-de-sponsoring-des-clubssportifs-a-I-\%C3\%A9preuve-de-I-\%C3\%A9pid\%C3\%A9mie-de-covid-19 . (29/5/2020).

- Dufourmantelle, Roger, La force majeure dans les contrats civils ou commerciaux et dans les marches administratifs (Paris: Giard et Briere, 1920), 12.

- DUMOND, Sandra.LA DATE ET LE CONTRAT. Thèse de doctorat, Université Lyon III, FACULTE DE DROIT, 2003. http://www.theses.fr/2003LYO33035. (15/3/2020).

- FAUCHOUX, Vincent. "COVID-19 | Coronavirus et force majeure : quels impacts sur vos contrats ?", Deprez Guignot Associates, "DDG", (2-3-2020). https://ddg.fr/actualite/coronavirus-et-force-majeure/ .(20/5/2020).

- FAUCHOUX. "COVID-19 | Coronavirus et force majeure",; Celine Taieb, "Contrat commerciaux et Coronavirus". Alaris Avocats (21-3-2020). https://www.alarislaw.com/fr/contrat-commerciaux-et-coronavirus/ .(22/5/2020).

- Grynbaum, Luc Grynbaum. "Force majeure et épidémie de COVID -19".de gaulle fleurance \& Associés (24/03/2020). www.degaullefleurance.com/force-majeure-etepidemie-de-covid-19/.(28/3/2020).

- Grynbaumm, Luc. "Force majeure et épidémie de COVID -19 : une première décision vient d'être rendue". le club des jurists (25 mars 2020).

https://www.leclubdesjuristes.com/blog-du-coronavirus/que-dit-le-droit/forcemajeure-et-epidemie-de-covid-19-les-premieres-decisions-viennent-detre-rendues/. (20/5/2020).

- Guiomard, Pascale. "La grippe, les épidémies et la force majeure en dix arrêts". dalloz (4/3/2020). https://www.dalloz-actualite.fr/flash/grippe-epidemies-et-force-majeureen-dix-arrets\#.Xs_uwzozblU.(15/4/2020).

- Haddad, Elsa. "Le coronavirus et ses conséquences sur les contrats, cas de force majeure ou cause d'imprévision ?", village de lajustice (27 mars 2020).https://www.villagejustice.com/articles/coronavirus-ses-consequences-sur-les-contrats-commerciaux-casforce-majeure,34373.html .(20/5/2020).

- JOAN DRAY. "L'épidémie de coronavirus constitue -il un événement de force majeure ?". legavox blog (26/3/2020). https://www.legavox.fr/blog/maitre-joan-dray/epidemiecoronavirus-constitue-evenement-force-28444.htm .(15/4/2020). 
- Jourdain, Patrice. "Le rôle de l'imprévisibilité de la cause étrangère". RTD Civ (1994): 871.https://actu.dallozetudiant.fr/fileadmin/actualites/pdfs/04._2017/rtd_civ_1994_87 1.pdf. (30/3/2020).

- $\quad$---. Force majeure : I'Assemblée plénière manque l'occasion d'une définition claire. Recueil Dalloz, (2006): 1577. https://actu.dallozetudiant.fr/fileadmin/actualites/pdfs/Juillet/D2006-1577.pdf. (30/3/2020).

- JULIEN, Philippe. "Coronavirus (Covid-19) : faut-il payer les loyers commerciaux du 2e trimestre 2020 ?". Editions Francis Lefebvre (19/3/2020).

https://www.efl.fr/actualites/affaires/biens-de-l-entreprise/details.html?ref=fe6303cfb7204-49e7-ab1b-98432000f5a5 .(15/4/2020).

- Landivaux, Ludovic. "Contrats et coronavirus : un cas de force majeure ? Ça dépend...". Dalloz (20 mars 2020). https://www.dalloz-actualite.fr/node/contrats-et-coronavirusun-cas-de-force-majeure-ca-depend\#.XqIOpY9OLIU. (29/3/2020).

- $\quad$ Latieule, Sophie. "COVID-19 ET LOCATIONS MEUBLÉES TOURISTIQUES : LES CONDITIONS D'ANNULATION À L'ÉPREUVE DE LA FORCE MAJEURE”. Fidal (7/4/ 2020) .https://www.fidal.com/fr/actualites/covid-19-et-locations-meublees-touristiques-lesconditions-dannulation-lepreuve-de-la .(15/4/2020).

- Leclercq, Catherine. “PEUT-ON S'EXONÉRER DU PAIEMENT DE SON LOYER COMMERCIAL DANS LE CONTEXTE DU COVID-19 ?". village justice (4/4/2020). https://www.villagejustice.com/articles/peut-exonerer-paiement-son-loyer-commercial-dans-contextecovid,34482.html\#nh2-1 .(15/4/2020).

- Ledoux, Valérie. "Coronavirus et (in)exécution des contrats d'affaires". racine avocats (2 Avril 2020): 1-4. https://www.racine.eu/wp-content/uploads/2020/04/coronavirus-etinexecution-du-contrat-daffaires-02042020-2.pdf.( 30/3/2020).

- Ledoux, Valérie. "Coronavirus et (in)exécution du contrat d'affaires", Racine Avocats(2 Avril 2020): 2. https://www.racine.eu/wp-content/uploads/2020/04/coronavirus-etinexecution-du-contrat-daffaires-02042020-2.pdf .(20/5/2020).

- Linais, Pierre. "La force majeure : un remède contre le COVID-19 ?". Stephenson Harwood (avril 2020). https://www.shlegal.com/news/la-force-majeure-unrem\%C3\%A8de-contre-le-covid-19.(20/5/2020).

- Makela, Roger Masamba. "L'IMPOSSIBLE ET LE CONTRAT". (2015): 1-12. http://www.daldewolf.com/documents/document/2015122111503247_52_roger_mas amba_I_x27_impossible_et_le_contrat_fv1_09_02_14.pdf.(15/3/2020).

- Marie-France STEINLE-FEUERBACH, Hervé ARBOUSSET, Marie-Pierre CAMPROUXDUFFRENE, Marie DEROCHE, Françoise GEISMAR, Valentine HEI NTZ, Caroline LACROIX et Claude LIENHA RD. INONDATIONS: RESPONSABILITES ET FORCE MAJEURE Colmar, France: Université de Haute-Alsace, 2002.

- Mathias, Avocats. "Covid-19 : un cas de force majeure ?". avocats-mathias (20 mars 2020). https://www.avocats-mathias.com/actualites/force-majeure-impacts-contrat .(20/5/2020). 
- Mazeaud, Léon et Henri Mazeaud, Traité théorique et pratique de la responsabilité civile, délictuelle et contractuelle, tome 2. Paris: Librairie du Recueil Sirey, société anonyme, 1934.

- MEDEF. "L'impact du Covid-19 dans les relations contractuelles", aacc, (10 mars 2020): 1-3 http://www.aacc.fr/uploads/file/file/000/000/770/12601-medef-impact-du-covid19-dans-les-relations-contractuelles.pdf. (29/3/2020).

- MOILLE, CÉLINE. "Force majeure et Covid-19 : une notion simple à invoquer en matière contractuelle ?". WOLTERS KLUWER FRANCE

(25/3/2020).https://www.actualitesdudroit.fr/browse/civil/contrat/26561/forcemajeure-et-covid-19-une-notion-simple-a-invoquer-en-matiere-contractuelle .(15/4/2020).

- Moisan, Pierre. "Technique contractuelle et gestion des risques dans les contrats internationaux :les cas de force majeure et d'imprévision". Les Cahiers de droit 35, n 2(1994): 281-334.https://core.ac.uk/download/pdf/59347623.pdf. (5/5/2020).

- Moury, Jacques. "Force majeure éloge de la sobriété", RTDciv : Revue Trimestrielle de droit civil, № 3 (2004): 471. https://halshs.archives-ouvertes.fr/halshs-02247568. (30/3/2020).

- Nicolas, Olivier. "Coronavirus : Peut-on invoquer la Force Majeure ?". echos (6 avril 2020).https://echos-judiciaires.com/actualite/tribune-coronavirus-forcemajeure/.(27/3/2020).

- NIVERT, Alexandre. "Entre COVID-19 et droit commun des contrats : la notion de force majeure". DOCTRIN'ACTU (23/3/2020). https://www.doctrinactu.fr/post/entre-covid19-et-droit-commun-des-contrats-la-notion-de-force-majeure .(28/3/2020).

- Planiol, Marcel et Georges Ripert.Traité pratique de droit civil français tome 7, 2ème edition .Paris: Librairie générale de droit et de jurisprudence, 1931.

- Rémy-Néris, Nicolas. "L'exécution des contrats commerciaux à l'épreuve du Covid-19", Grant Thornton (1-4-2020). https://www.grantthornton.fr/fr/insights/articles-etpublications/2020/lexecution-des-contrats-commerciaux-a-lepreuve-du-covid-19/ .(22/5/2020).

- Rossi-Landi, Romain. "Non-paiement des loyers : ce que prévoit le droit pour les baux commerciaux. BFM Immo (25/3/2020). http://rossi-landiavocat.fr/2020/03/25/nonpaiement-des-loyers-ce-que-prevoit-le-droit-pour-les-baux-commerciaux/ .(15/4/2020).

- Sabatier, David. "La résiliation des contrats pour force majeure en raison du covid-19 / coronavirus", 1862 Avocats. https://www.1862-legal.com/blog-avocat-droitimmobilier/2020/3/15/doit-on-sattendre-une-vague-de-rsiliation-des-contrats-pourforce-majeure-en-raison-du-covid-19-coronavirus- .(20/5/2020).

- Sériaux, Alain. DROIT DES OBLIGATIONS, 2ème edition. Paris: Presses universitaires de France (PUF), 1998), 244.

- Sévère , Christine et Claire Picard. "COVID-19 Force majeure, fait du prince, imprévision et exception d'inexécution", Dentons (19 mars 2020).https://www.dentons.com/fr/insights/alerts/2020/march/19/covid-19-forcemajeure-contingency-and-default-exception .(20/5/2020). 
- Sévère, Christine et Claire Picard."COVID-19 Force majeure, fait du prince, imprévision et exception d'inexécution", dentons (19-3-

2020).https://www.dentons.com/fr/insights/alerts/2020/march/19/covid-19-forcemajeure-contingency-and-default-exception .(22/5/2020).

- Tavennec, Séverine. "Contrats et covid-19 : quid de la force majeure ?". Le petit jurist (3/4/2020). https://www.lepetitjuriste.fr/contrats-et-covid-19-quid-de-la-forcemajeure/ .(15/4/2020).

- TOUAHRI, Assia. La responsabilité civile du fait du dommage nucléaire civil. thèse de doctorat, UNIVERSITE DE LIMOGES, Faculté de Droit et des Sciences Economiques, 2018.

- Touzet, Philippe et Maya Dami. "Covid-19 : une application pratique de la force majeure".(6 Avril 2020). https://www.parabellum.pro/Covid-19-une-applicationpratique-de-la-force-majeure_a856.html. (20/5/2020).

- Tunc, André. "Force majeure et absence de faute en matière délictuelle", RTD Civ (1946).187.

- VAN ZUYLEN, Jean. "La force majeure en matière contractuelle: un concept unifié? Réflexions à partir des droits belge, français et hollandaise", Revue Générale de Droit Civil Belge (RGDC), (Août 2013): 406-

421.https://dial.uclouvain.be/pr/boreal/object/boreal:124936?site_name=USL-B. (20/5/2020).

- VAN ZUYLEN, Jean. "La force majeure en matière contractuelle: unconcept unifié? Réflexions à partir des droits belge, français et hollandaise". Revue Générale de Droit Civil Belge - Kluwer, TBBR/RGDC (2013): 406-

421.https://dial.uclouvain.be/pr/boreal/object/boreal\%3A124936/datastream/PDF_01/ view. (15/3/2020). 